\title{
Kinetic and Structural Characterization of a Heterohexamer 4- Oxalocrotonate Tautomerase from Chloroflexus aurantiacus J-10-fl: Implications for Functional and Structural Diversity in the Tautomerase Superfamily ${ }^{\dagger}$
}

\author{
Elizabeth A. Burks ${ }^{\ddagger}$, Chris D. Fleming $\S$, Andrew D. Mesecar§, Christian P. Whitman ${ }^{\ddagger}{ }^{*}$, and \\ Scott D. Pegan $\$, \|,{ }^{*}$ \\ ‡ Division of Medicinal Chemistry, College of Pharmacy, University of Texas at Austin, Texas \\ 78712 \\ $\S$ Center for Pharmaceutical Biotechnology, (MC 870), College of Pharmacy, University of Illinois \\ at Chicago, 900 South Ashland Avenue, Chicago, Illinois 60607-7173 \\ II Department of Chemistry and Biochemistry, University of Denver, Denver, Colorado, \\ 80208-0183
}

\section{Abstract}

\begin{abstract}
4-Oxalocrotonate tautomerase (4-OT) isozymes play prominent roles in the bacterial utilization of aromatic hydrocarbons as sole carbon sources. These enzymes catalyze the conversion of 2hydroxy-2,4-hexadienedioate (or 2-hydroxymuconate) to 2-oxo-3-hexenedioate, where Pro-1 functions as a general base and shuttles a proton from the 2-hydroxyl group of substrate to the C-5 position of product. 4-OT, a homohexamer from Pseudomonas putida mt-2, is the most extensively studied 4-OT isozyme and the founding member of the tautomerase superfamily. A search of five thermophilic bacterial genomes identified a coded amino acid sequence in each that had been annotated as a tautomerase-like protein but lacked Pro-1. However, a nearby sequence has Pro-1, but the sequence is not annotated as a tautomerase-like protein. In order to characterize
\end{abstract}

\footnotetext{
$\dagger$ This research was supported by the National Institutes of Health Grants GM-41239 (CPW) and AI-60915 (SDP), the Robert A. Welch Foundation grant F-1334 (CPW), and the Department of Defense Grant W81XWH0710445 USAMRAA (SDP). Use of the Advanced Photon Source is supported by the US Department of Energy, Office of Science, Office of Basic Energy Sciences, under Contract N. W-31-109-Eng-38. The Analytical Instrumentation Facility Core (College of Pharmacy, The University of Texas at Austin) is supported by an NIH Center grant ES07784.

"Corresponding authors (CPW) Tel: 512-471-6198; Fax: 512-232-2606; whitman@mail.utexas.edu. (SDP) Tel: 303-871-2533; Fax: 303-871-2254; scott.pegan@du.edu.

The atomic coordinates and structure factors have been deposited with the Brookhaven Protein Data Bank (PDB codes 3MB2).

${ }_{1}^{1}$ Abbreviations: Ap, ampicillin; BSA, bovine serum albumin; dNTPs, deoxyribose nucleotide triphosphates; CHMI, 5-

(carboxymethyl)-2-hydroxymuconate isomerase; $\mathrm{CaaD}$, trans-3-chloroacrylic acid dehalogenase; cis-CaaD, cis-3-chloroacrylic acid dehalogenase; DSC, differential scanning calorimetry; HEPES, N-2-hydroxyethylpiperazine-N'-2-ethane sulfonate; hh4-OT, heterohexamer 4-oxalocrotonate tautomerase; IPTG, isopropyl- $\beta$-D-thiogalactoside; Kn, kanamycin; LB, Luria-Bertani; MIF, macrophage migration inhibitory factor; MSAD, malonate semialdehyde decarboxylase; NCBI, National Center for Biotechnology Information; NMR, nuclear magnetic resonance; 4-OT, 4-oxalocrotonate tautomerase; PEG, polyethylene glycol; PPT, phenylpyruvate tautomerase; PCR, polymerase chain reaction; SDS-PAGE, sodium dodecyl sulfate-polyacrylamide gel electrophoresis.

SUPPORTING INFORMATION AVAILABLE

The expression, overproduction, and purification protocols for the hh4-OT are provided in the Supporting Information. The experimental procedures used for the construction, expression, overproduction, purification, and mass spectral analysis of the hh4-OT mutants and the construction and expression of the separate subunits of the hh4-OT are also provided in the Supporting Information. Finally, the molecular modeling studies are described. This material is available free of charge via the Internet at http://pubs.acs.org.
} 
this group of proteins, two genes from Chloroflexus aurantiacus J-10-fl were cloned, and the corresponding proteins expressed. Kinetic, biochemical, and X-ray structural analysis show that the two expressed proteins form a functional heterohexamer 4-OT (hh4-OT), composed of three $\alpha \beta$ dimers. Like the $P$. putida enzyme, the hh4-OT requires the amino-terminal proline and two arginines for the conversion of 2-hydroxymuconate to product, implicating an analogous mechanism. In contrast to 4-OT, the hh4-OT does not exhibit the low-level activity of another tautomerase superfamily member, the heterohexamer trans-3-chloroacrylic acid dehalogenase $(\mathrm{CaaD})$. Characterization of the hh4-OT enables functional assignment of the related enzymes, highlights the diverse ways the $\beta-\alpha-\beta$ building block can be assembled into an active enzyme, and provides further insight into the molecular basis of the low level CaaD activity in 4-OT.

4-Oxalocrotonate tautomerase (4-OT), initially cloned from the TOL plasmid pWW0 in Pseudomonas putida mt-2, catalyzes the conversion of 2-hydroxy-2,4-hexadienedioate, known more commonly as 2-hydroxymuconate (1, Scheme 1) to 2-oxo-3-hexenedioate (2) (1-5). The enzyme is part of the meta-fission pathway, which is a catabolic pathway for aromatic hydrocarbons. Organisms having the TOL plasmid can process simple aromatic hydrocarbons (e.g., benzene, toluene, $m$ - and $p$-xylene, 3-ethyltoluene, and 1,2,4trimethylbenzene) as their sole sources of carbon and energy (3).

4-OT is a member of the tautomerase superfamily, which is a group of structurally homologous proteins, characterized by a $\beta-\alpha-\beta$ scaffold and a catalytic amino-terminal proline (6-11). There are five known families of this superfamily represented by the key members, 4-OT, 5-(carboxymethyl)-2-hydroxymuconate isomerase (CHMI), macrophage migration inhibitory factor (MIF) (7,8), cis-3-chloroacrylic acid dehalogenase (cis-CaaD) (9), and malonate semialdehyde decarboxylase (MSAD) (10). The 4-OT family includes trans-3-chloroacrylic acid dehalogenase (CaaD). Superfamily members have been described as trimers (CHMI, MIF, cis-CaaD and MSAD), a heterohexamer (CaaD), a homodimer (a 4OT homologue designated YdcE) (11) and homohexamers (4-OT and a 4-OT homologue designated $\mathrm{YwhB})(7,8)$. These enzymes mediate tautomerization, dehalogenation, hydration, and decarboxylation reactions. Thus far, Pro- 1 is a critical residue for the activities of all of these enzymes.

In the course of a search for other superfamily members, the genomes of five recently sequenced thermophilic organisms showed an intriguing peculiarity: each had a protein annotated as a 4-OT homologue in what appeared to be a catabolic pathway for aromatic hydrocarbons, but the homologue lacked Pro- $1^{2}$. Moreover, each organism had a second protein of similar length in the vicinity of the hypothetical tautomerase with the aminoterminal proline, but these sequences were not annotated as tautomerase-like. Because it was not immediately obvious what role these two proteins might play, the corresponding genes were cloned from Chloroflexus aurantiacus $\mathrm{J}-10-\mathrm{fl}$, and the two proteins produced and characterized. The proteins form an $\alpha \beta$ dimer and the active tautomerase is a heterohexamer, which converts 1 to 2 , and phenylenolpyruvate (3, Scheme 1$)$ to phenylpyruvate (4). Mutagenesis analysis implicates $\beta$ Pro- $1, \alpha$ Arg-12, and $\alpha$ Arg- 40 as critical residues for these activities whereas $\beta$ Arg- 11 and $\beta$ Arg-39 are not required for activity. A crystal structure confirms the heterohexamer arrangement and shows that the active site contains $\beta$ Pro- 1 , $\alpha$ Arg-12 and $\alpha$ Arg- 40 . Despite the mechanistic parallels and active site similarities, the hh4OT lacks a significant property of 4-OT - it does not have a low level CaaD activity. This is the first reported 4-OT heterohexamer and its properties have implications for the evolution of other superfamily members.

\footnotetext{
${ }^{2}$ The initiating methionine is the first amino acid according to the gene sequence. However, proteins with a proline in the second position undergo post-translational modification to remove the initiating methionine, so that proline becomes the amino-terminal amino acid (12).
} 


\section{EXPERIMENTAL PROCEDURES}

\section{Materials}

Chemicals, biochemicals, buffers, and solvents were purchased from Sigma-Aldrich

Chemical Co. (St. Louis, MO), Fisher Scientific Inc. (Pittsburgh, PA), Fluka Chemical Corp. (Milwaukee, WI), or EM Science (Cincinnati, $\mathrm{OH}$ ). The Centricon and Ultrafree centrifugal filter devices were obtained from Millipore Co. (Billerica, MA). The synthesis of 2hydroxymuconate (1) is reported elsewhere (4). Recombinant 4-OT, cloned from the TOL plasmid of $P$. putida mt-2 and expressed in Escherichia coli strain BL21-Gold(DE3), was purified by modifying previously reported procedures $(13,14)$, as reported in the Supporting Information. The Phenyl Sepharose 6 Fast Flow and the Sephacryl-S100 High Resolution resins were obtained from GE Healthcare (Piscataway, NJ). The Econo-Column ${ }^{\circledR}$ chromatography columns and Freeze ' $\mathrm{N}$ Squeeze units, used for extraction of DNA from agarose gels, were obtained from Bio-Rad Laboratories, Inc. (Hercules, CA). Enzymes and reagents used for molecular biology procedures were obtained from New England Biolabs, Inc. (Ipswich, MA). The sources for the components of Luria-Bertani (LB) media are reported elsewhere (15).

\section{Bacterial Strains, Plasmids, and Growth Conditions}

C. aurantiacus $\mathrm{J}-10-\mathrm{fl}$ was provided by Dr. Michael T. Madigan (16). Cells of the strain were grown at $50{ }^{\circ} \mathrm{C}$ under a tungsten light as described elsewhere (16). The cells were stored at $-80{ }^{\circ} \mathrm{C}$ until ready for use. E. coli strain DH5 $\alpha$ was obtained from Invitrogen (Carlsbad, CA). E. coli strain BL21-Gold(DE3) and the pBluescript II SK ${ }^{-}$were obtained from Stratagene (La Jolla, CA). The pET vectors were obtained from Novagen (Madison, WI).

\section{General Methods}

Techniques for restriction enzyme digestion, ligation, transformation, and other standard molecular biology manipulations were based on methods described elsewhere (15).

Oligonucleotide primers were synthesized by Invitrogen. DNA sequencing was performed at the DNA core facility of the Institute for Cellular and Molecular Biology at the University of Texas at Austin. Mass spectral data were obtained on an LCQ electrospray ion-trap mass spectrometer (Thermo, San Jose, CA) in the Analytical Instrumentation Facility Core in the College of Pharmacy at the University of Texas at Austin. Samples were prepared as described elsewhere (17). Kinetic data were obtained at $24{ }^{\circ} \mathrm{C}$ on an Agilent 8453 diodearray spectrophotometer. Nonlinear regression data analysis was performed using the program Grafit (Erithacus Software Ltd., Staines, U.K.) obtained from Sigma-Aldrich. Plasmids were isolated from cell cultures using the QIAprep Miniprep Kit (Qiagen, Valencia, CA). Protein concentrations were determined by the method described by Waddell (18). Protein was analyzed by tricine sodium dodecyl sulfate-polyacrylamide gel electrophoresis (SDS-PAGE) on 15\% T/2\%C gels on a vertical gel electrophoresis apparatus obtained from Idea Scientific (Minneapolis, MN) (19). BLAST and iterative PSI-BLAST searches of the National Center for Biotechnology Information (NCBI) databases were performed using the 4-OT amino acid sequence from the TOL plasmid of $P$. putida $\mathrm{mt}-2$ as the query sequence (13). Nuclear magnetic resonance (NMR) spectra were recorded in $100 \% \mathrm{H}_{2} \mathrm{O}$ on a Varian Unity INOVA-500 spectrometer as reported previously (17).

\section{Cloning of the $\alpha$ - and $\beta$-Subunits of the hh4-OT from Genomic DNA}

Genomic DNA was extracted from $50 \mathrm{mg}$ of cells following a protocol described elsewhere (20). The coding regions for the two subunits were amplified from genomic DNA in separate PCRs ${ }^{3}$. Each PCR mixture $(50 \mu \mathrm{L})$ contained genomic DNA $(0.5 \mu \mathrm{g})$, two 5'- 
phosphorylated primers for blunt cloning $(0.4 \mu \mathrm{M})$, dNTPs $(0.3 \mathrm{mM})$, bovine serum albumin (BSA, $0.5 \mathrm{mM}$ ), Vent polymerase ( 0.5 unit), and the accompanying $10 \mathrm{X}$ buffer (diluted to $1 \mathrm{X})$. For the $\alpha$-subunit, the forward primer $(\alpha \mathrm{G} 1)$ had the sequence $5^{\prime}$ -

GGACGGTGATATGCTACTTC-3' and the reverse primer $(\alpha \mathrm{G} 2)$ had the sequence $5^{\prime}$ GTTCTGAACAAACGAGTTAC- $3^{\prime}$. For the $\beta$-subunit, the forward primer $(\beta G 1)$ had the sequence $5^{\prime}$-CTCCACTTACGGTTCGTGTG- 3 ' and the reverse primer $(\beta G 2)$ had the sequence 5'-CGCTTTACCCATCACCTATC- 3 '. The primers were designed to match the areas just upstream and downstream of the coding region of each subunit. The PCR amplification protocol consisted of an initial 5-min denaturation cycle at $94^{\circ} \mathrm{C}$, followed by 29 cycles of $94{ }^{\circ} \mathrm{C}$ for $1 \mathrm{~min}, 55^{\circ} \mathrm{C}$ for $2 \mathrm{~min}$, and $72{ }^{\circ} \mathrm{C}$ for $3 \mathrm{~min}$, a 10 -min elongation cycle at $72{ }^{\circ} \mathrm{C}$, and ending with a hold at $4{ }^{\circ} \mathrm{C}$. The gel-purified PCR products were ligated into an $E c o R \mathrm{~V}$-digested pBluescript II $\mathrm{SK}^{-}$. An aliquot of each ligation mixture was used to transform E. coli DH5 $\alpha$ cells by electroporation. A positive colony resulting from each transformation mixture was selected based on PCR screening. The plasmid from each colony was isolated, sequenced, and designated the $\alpha$ - or $\beta$-genomic clone.

\section{Construction of the Bluescript hh4-OT Dicistronic Vector}

The $\alpha$-subunit was amplified by the PCR from the corresponding $\alpha$-genomic clone using the oligonucleotide $5^{\prime}$ -

TAGTAGTAGGAATTCAAGAAGGAGATATACATATGCTACTTC- $3^{\prime}$ as the forward primer and the $\alpha \mathrm{G} 2$ primer (above) as the reverse primer. The forward primer contains nine nonspecific bases (to enhance restriction enzyme digestion efficiency), a ribosome binding site, an NdeI restriction site (underlined), and seven additional gene-specific bases. The PCR mixture $(50 \mu \mathrm{L})$ contained the $\alpha$-genomic clone (12 ng of plasmid), primers $(0.2 \mu \mathrm{M})$, dNTPs $(0.2 \mathrm{mM})$, BSA, (0.5 mM), Vent polymerase (0.5 unit), and the accompanying 10X buffer (diluted to 1X). The PCR amplification protocol consisted of an initial 2-min denaturation cycle at $94^{\circ} \mathrm{C}$, followed by 29 cycles of $94{ }^{\circ} \mathrm{C}$ for $1 \mathrm{~min}, 55^{\circ} \mathrm{C}$ for $2 \mathrm{~min}$, and $72{ }^{\circ} \mathrm{C}$ for $3 \mathrm{~min}$, and ended with a 10 -min elongation cycle at $72{ }^{\circ} \mathrm{C}$, followed by a hold at 4 ${ }^{\circ} \mathrm{C}$. The gel-purified product was phosphorylated and blunt cloned into pBluescript II SK ${ }^{-}$at the $E c o R V$ site. The resulting clone lacked the first 16 bases of the forward primer and had the $\alpha$-subunit oriented such that an EcoRI site of the vector was at the $3^{\prime}$ end of the gene.

The $\beta$-subunit was amplified by the PCR from the $\beta$-genomic clone using the oligonucleotides 5'-

TAGTAGTAGGAATTCAAGAAGGAGATATACATATGCCGATGC-3' ${ }^{\prime}$ and 5'GATGATGATCTCGAGGGATCCTCATTATTACTGCTGGTCTGGC-3' as the forward and reverse primers, respectively. The forward primer contains nine nonspecific bases, an EcoRI restriction site (underlined), a ribosome binding site, an $N d e$ I restriction site (italicized), and seven gene specific bases. The reverse primer contains nine nonspecific bases, an XhoI restriction site (underlined), a BamHI restriction site (italicized), three stop codons, and ten gene-specific bases. The PCR mixture $(100 \mu \mathrm{L})$ contained the $\beta$-genomic clone ( $1 \mu \mathrm{L}$ of gel extract), the primers $(0.2 \mu \mathrm{M})$, dNTPs $(0.2 \mathrm{mM})$, Vent polymerase (1 unit), and the accompanying 10X buffer (diluted to $1 \mathrm{X}$ ). Two separate reactions were carried out using a PCR amplification protocol that consisted of an initial 2-min denaturation cycle at $94^{\circ} \mathrm{C}$, followed by 25 cycles of $94^{\circ} \mathrm{C}$ for $45 \mathrm{~s}, 55^{\circ} \mathrm{C}$ for $45 \mathrm{~s}$, and $72{ }^{\circ} \mathrm{C}$ for $2 \mathrm{~min}$, and ended with a 10-min elongation cycle at $72{ }^{\circ} \mathrm{C}$, followed by a hold at $4{ }^{\circ} \mathrm{C}$.

The product was cloned into the pBluescript construct containing the $\alpha$-subunit between the EcoRI and BamHI restriction sites as follows. The gel-purified PCR product and the

\footnotetext{
${ }^{3}$ The sequence of the genomic DNA was obtained from the NCBI web site (accession number NC_010175). The protein accession numbers are YP_001634971 (GI:163846927) for the $\alpha$-subunit (which appears first in the genome) and YP_001634975 (GI: 163846931) for the $\beta$-subunit.
} 
pBluescript construct containing the $\alpha$-subunit were treated with EcoRI and BamHI restriction enzymes, purified, and ligated using T4 DNA ligase. Aliquots of the ligation mixture were used to transform competent $E$. coli DH5 $\alpha$ cells. Transformants were selected at $37^{\circ} \mathrm{C}$ on $\mathrm{LB} / \mathrm{Ap}(100 \mu \mathrm{g} / \mathrm{mL})$ plates. Plasmid was isolated from one clone, sequenced, and used for the production of hh4-OT.

\section{Cloning of the Dicistronic Gene for the hh4-OT into pET24a}

The dicistronic gene for the hh4-OT was amplified from the pBluescript construct (containing the dicistronic gene) by the PCR using the forward primer 5'TAGTAGTAGTCTAGAGGTATCGATAAGCTTG-3' and the reverse primer 5'GATGATGATCTCGAGACTAGTGGATCC-3'. The forward primer contains nine

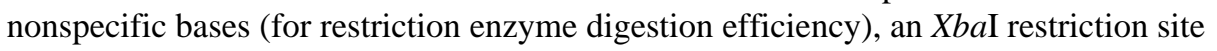
(underlined), and sixteen bases specific for the $5^{\prime}$-end of the dicistronic gene in the pBluescript construct. The reverse primer contains nine nonspecific bases (for restriction site digestion efficiency), an XhoI restriction site (underlined), and twelve bases specific for the $3^{\prime}$-end of the dicistronic gene in the pBluescript construct. The PCR mixture $(200 \mu \mathrm{L})$ contained the pBluescript construct $(160 \mathrm{ng})$, the primers $(0.5 \mu \mathrm{M})$, dNTPs $(0.2 \mathrm{mM})$, Taq polymerase ( 6 units), and the accompanying $10 \mathrm{X}$ buffer (diluted to $1 \mathrm{X}$ ). The PCR amplification protocol consisted of an initial 2-min denaturation cycle at $94^{\circ} \mathrm{C}$, followed by 29 cycles of $94{ }^{\circ} \mathrm{C}$ for $1 \mathrm{~min}, 55^{\circ} \mathrm{C}$ for $2 \mathrm{~min}$, and $72{ }^{\circ} \mathrm{C}$ for $3 \mathrm{~min}$, and ended with a 10-min elongation cycle at $72{ }^{\circ} \mathrm{C}$, followed by a hold at $4{ }^{\circ} \mathrm{C}$. The gel-purified PCR product and the pET24a vector were treated with $\mathrm{XbaI}$ and $\mathrm{XhoI}$ restriction enzymes, purified, and ligated using T4 DNA ligase. Aliquots of the ligation mixture were used to transform competent $E$. coli DH5 $\alpha$ cells. Transformants were selected at $37^{\circ} \mathrm{C}$ on $\mathrm{LB} / \mathrm{Kn}(30 \mu \mathrm{g} / \mathrm{mL})$ plates. Two colonies were randomly chosen for sequencing. Both clones showed the correct sequences for the $\alpha$ - and $\beta$-dicistronic gene arrangement. Plasmid DNA was isolated from one clone and used as the expression vector in E. coli BL21-Gold(DE3) cells.

\section{Expression and Purification of hh4-OT and Construction, Expression, and Purification of the hh4-OT Mutants}

The expression, overproduction, and purification protocols for the hh4-OT are provided in the Supporting Information. The experimental procedures used for the construction, expression, overproduction, purification, and mass spectral analysis of the hh4-OT mutants are also provided in the Supporting Information.

\section{Enzyme Assays and Kinetic Studies}

The tautomerization activities of hh4-OT were measured by monitoring the ketonization of $\mathbf{1}$ to $\mathbf{2}$ and 3 to 4 in $10 \mathrm{mM}$ potassium phosphate buffer, pH 7.3 at $24{ }^{\circ} \mathrm{C}(4,5)$. Stock solutions $(20 \mathrm{mM})$ of 2-hydroxymuconate (1) and phenylenolpyruvate (3) were made up in ethanol, and diluted (with ethanol) to $10 \mathrm{mM}$. The ketonization of $\mathbf{1}$ to $\mathbf{2}$ was measured by following the increase in absorbance at $236 \mathrm{~nm}\left(\varepsilon=6580 \mathrm{M}^{-1} \mathrm{~cm}^{-1}\right)$ using substrate concentrations ranging from 10-200 $\mu \mathrm{M}$ (4). The ketonization of $\mathbf{3}$ to $\mathbf{4}$ was measured by following the decrease in absorbance at $283 \mathrm{~nm}\left(\varepsilon=18,000 \mathrm{M}^{-1} \mathrm{~cm}^{-1}\right)$ using substrate concentrations ranging from 10-140 $\mu \mathrm{M}(5)$. An aliquot of enzyme was diluted into the potassium phosphate buffer, yielding a final dimer concentration of 1-191 nM for reactions using 1 and $100-1000 \mathrm{nM}$ for reactions using 3 . Reactions were initiated by the addition of substrate.

The spectrophotometric assay used to monitor the dehalogenation of trans- or cis-3chloroacrylic acid was modified from previously reported protocols $(17,21)$. Accordingly, reaction mixtures containing $10 \mathrm{mM}$ potassium phosphate buffer, $\mathrm{pH} 7.3$, substrate (transor cis-3-chloroacrylic acid, $0.5 \mathrm{mM}$ ), and enzyme (wild type, $\beta \mathrm{R} 11 \mathrm{~A}$ mutant, and $\beta \mathrm{R} 39 \mathrm{~A}$ mutant) were allowed to incubate at room temperature. An aliquot of enzyme was diluted 
into the potassium phosphate buffer, yielding a final dimer concentration of $4.5 \mu \mathrm{M}, 5.0 \mu \mathrm{M}$, and $4.9 \mu \mathrm{M}$ respectively for the wild type, $\beta \mathrm{R} 11 \mathrm{~A}$ mutant, and $\beta \mathrm{R} 39 \mathrm{~A}$ mutant enzymes.

After 2 weeks, there was no change in the absorbance at $224 \mathrm{~nm}$.

\section{${ }^{1} \mathrm{H}$ NMR Spectroscopic Monitoring of the Incubation Mixture Containing hh4-OT and trans-3-Chloroacrylic Acid (5)}

The ${ }^{1} \mathrm{H}$ NMR experiments were carried out as previously reported $(17,22)$, with the following modifications. Accordingly, an aliquot $(0.6 \mathrm{~mL})$ of 5 (Scheme 2 ) was transferred to an NMR tube from a stock solution made up in $100 \mathrm{mM} \mathrm{Na}_{2} \mathrm{HPO}_{4}$ buffer. The aliquot contained $4 \mathrm{mg}(0.04 \mathrm{mmol})$ of the substrate. DMSO- $d_{6}(30 \mu \mathrm{L})$ was also added to the tube. The $\mathrm{pH}$ of the reaction mixture was then adjusted to 9.3 using small amounts of an aqueous $1 \mathrm{M} \mathrm{NaOH}$ solution. Subsequently, an aliquot of hh4-OT $(50 \mu \mathrm{L}$ of a $5.6 \mathrm{mg} / \mathrm{mL}$ solution of hh4-OT) from a solution made up in $20 \mathrm{mM} \mathrm{Na}_{2} \mathrm{HPO}_{4}$ buffer, $\mathrm{pH} 7.3$ was added to the reaction mixture. ${ }^{1} \mathrm{H}$ NMR spectra were recorded 10 days and 7 weeks after the addition of enzyme to the NMR tube. At both intervals, the enzyme was examined for hh4-OT activity using 1 and found to be active.

\section{Enzymatic Activity as a Function of the Oligomer State}

The construction of pET24a vectors containing individual $\alpha$ - and $\beta$-subunits is described in the Supporting Information. The genes were then expressed separately in E. coli BL21Gold(DE3) cells, the separate $\alpha$ - and $\beta$-subunits partially purified, and examined for activity (using 1) before and after treatment with $8 \mathrm{M}$ urea. Accordingly, the cells ( 2-4 g each) were suspended in $20 \mathrm{mM}$ HEPES buffer $(\sim 10 \mathrm{~mL}, \mathrm{pH}$ 7.6). The individual suspensions were sonicated and protease inhibitors added (see Supporting Information). The lysed cell mixtures were centrifuged for $45 \mathrm{~min}(30,000 \mathrm{~g})$, followed by recovery of the supernatants, which were then centrifuged for $3 \mathrm{~h}(264,000 \mathrm{~g})$. The individual supernatants (containing $\alpha$ or $\beta$-subunit) were treated with urea in separate tubes by mixing supernatant $(0.09 \mathrm{~mL})$ with urea $(0.4 \mathrm{~mL}$ of $10 \mathrm{M}$ urea in $20 \mathrm{mM}$ HEPES buffer, $\mathrm{pH} 7.3)$. A small amount of $\mathrm{NaCl}(0.01$ $\mathrm{mL}$ of a $5 \mathrm{M} \mathrm{NaCl}$ in $20 \mathrm{mM}$ HEPES buffer, $\mathrm{pH}$ 7.3) was added to each sample. Rapid dilution was achieved by mixing an aliquot $(10 \mu \mathrm{L})$ into $1 \mathrm{~mL}$ of $10 \mathrm{mM} \mathrm{KH} \mathrm{PO}_{4}$ buffer $(\mathrm{pH}$ 7.3). The sample was then assayed for activity using $1(10 \mu \mathrm{L}$ of a $20 \mathrm{mM}$ solution of 1). In addition to these samples, a mixture of the urea-treated $\alpha$ - and $\beta$-subunits $(\sim 1: 1)$ was rapidly diluted and assayed, as described above. Each sample was examined by SDS-PAGE $(15 \% \mathrm{~T} / 2 \% \mathrm{C}$ gels) to verify the presence of two proteins of the correct molecular masses.

\section{Crystallization and Structural Determination of hh4-OT}

The initial crystallization conditions for hh4-OT were determined from the high-throughput screening of Qiagen Nextel screens, Classics, Classics II, polyethylene glycol (PEG)s, and PEGs II suites, with a Tecan Freedom Evo 200 liquid handling robot. The hh4-OT (20 mg/ $\mathrm{mL}$ in $10 \mathrm{mM} \mathrm{Na} / \mathrm{KPO}_{4}$ buffer, $\mathrm{pH}$ 7.3) was mixed in a 1:1 ratio with precipitant to give a total volume of $2 \mu \mathrm{L}$ in a sitting drop formatted microplate with a $100 \mu \mathrm{L}$ reservoir solution. Final crystals for hh4-OT were obtained by the hanging drop vapor diffusion method with a $500-\mu \mathrm{L}$ reservoir and $4 \mu \mathrm{L}$ hanging drops that contained protein and precipitant, $0.25 \mathrm{M}$ $\left(\mathrm{NH}_{4}\right)_{2} \mathrm{SO}_{4}$ and $4 \%$ PEG 4000, in a 1:1 ratio. Crystals appeared in the course of 3-5 days.

The X-ray diffraction data were collected on the hh4-OT crystals to $2.41 \AA$ resolution at the Argonne National Laboratories (Argonne, IL) on the Southeast Regional Collaborative Access Team (SER-CAT) beamline 22-BM. Crystals were mounted on nylon loops and submerged in a $4 \mu \mathrm{L}$ drop of a cryo solution containing $0.25 \mathrm{M}\left(\mathrm{NH}_{4}\right)_{2} \mathrm{SO}_{4}$ and $25 \%$ PEG 4000. The crystals were then immediately flash-frozen by submerging them in liquid nitrogen. The flash-frozen crystals were mounted on a goniostat under a stream of dry $\mathrm{N}_{2}$ at $100{ }^{\circ} \mathrm{K}$. X-ray exposures of $1 \mathrm{~s}$ per degree of rotation about $200^{\circ}$ omega were collected on a 
MAR 225 CCD detector. The X-ray data were processed and scaled using HKL2000 (23). The data collection statistics are presented in Table 1.

The molecular replacement solutions were determined using PHASER (24). The overall search model was based on the heterohexamer CaaD (3EJ7) comprised of an $\alpha$-subunit homology model produced by 3D-Jigsaw using a 4OT homolog, Haemophilus influenzae (1MWW) and a $\beta$-subunit hh4-OT homology model derived from MODELLER using the Pseudomonas sp CF600 4OT isozyme (1OTF) (25-27). WINCOOT was used for model building and REFMAC from the CCP4 software suite was used for restrained TLS refinement using 36 TLS groups $(24,28)$. The refinement statistics are presented in Table 1.

\section{Differential Scanning Calorimetry}

Samples of hh4-OT from C. aurantiacus J-10-fl and 4OT from P. putida mt-2 were filtered through a $0.22 \mu \mathrm{m}$ syringe filter following overnight dialysis into $10 \mathrm{mM}$ sodium phosphate buffer ( $\mathrm{pH}$ 7.3). The protein samples were subsequently diluted using the same buffer to concentrations of $0.14 \mathrm{mg} / \mathrm{mL}(299 \mu \mathrm{M}$ in heterohexamer) for the hh4-OT and $0.21 \mathrm{mg} / \mathrm{mL}$ (524 $\mu \mathrm{M}$ in homohexamer) for the $P$. putida $\mathrm{mt}-2$ 4-OT. Heat capacity measurements were carried out using a VP-DSC differential scanning calorimeter (Microcal, Northampton, MA) over a temperature range of $10-125^{\circ} \mathrm{C}$ under $\sim 28 \mathrm{psi}(1.9 \mathrm{~atm})$. Samples were heated at a rate of $90^{\circ} \mathrm{C} / \mathrm{h}$. An accurate baseline was derived from 5 buffer-buffer scans, which was subtracted respectively from five scans performed on each enzyme. Heat capacity was plotted versus temperature to determine the temperature of maximal heat capacity $\left(\mathrm{T}_{m}\right)$ for both protein samples after normalizing for the protein concentrations. Origin 5.0 was used for all differential scanning calorimetry (DSC) data analysis.

\section{RESULTS}

\section{Sequence Analysis for the hh4-OT Homologues}

A sequence similarity search of the NCBI database was performed with the BLASTP program using the 4-OT amino acid sequence from the TOL plasmid of $P$. putida $\mathrm{mt}-2$ as the query sequence (13). The search yielded a sequence from Roseiflexus sp. RS-1 [genbank accession YP_001276901] that was annotated as a tautomerase-like protein, but showed a leucine rather than a proline following the initiating methionine. Examination of the genomic context for this gene (GI:148656696) using the genome project link at the NCBI web site revealed the presence of the genes coding enzymes similar to the ones surrounding 4-OT in the TOL plasmid including 2-hydroxymuconate semialdehyde dehydrogenase (which precedes 4-OT in the meta-fission pathway) and 4-oxalocrotonate decarboxylase and vinylpyruvate hydratase (which follow 4-OT in the meta-fission pathway) (1-3). Using the Roseiflexus sp. RS-1 sequence as the query sequence in a BLAST search yielded several highly similar sequences (40-59\% sequence similarity) that were also annotated as tautomerase-like proteins, but none had a proline following the initiating methionine (Figure 1A). Examination of the genomic context of each also showed genes encoding proteins typically associated with the meta-fission pathway as well as a hypothetical protein with approximately the same number of amino acid residues (63-73 amino acids) (Figure 1B). Examination of the sequence of each of these hypothetical proteins showed that they have a proline following the initiating methionine, but apparently the sequences do not trigger the tautomerase designation by the BLAST domain search. This study indicated that the first set of sequences (Figure 1A) likely corresponds to the $\alpha$-subunit of a hh4-OT and the second set of sequences (Figure 1B) likely corresponds to the $\beta$-subunit of a hh4-OT. The $\alpha$ - and $\beta$ subunits of the C. aurantiacus $\mathrm{J}-10-\mathrm{fl}$ hh4-OT share $\sim 44 \%$ sequence similarity and $\sim 22 \%$ sequence identity. 


\section{Expression, Purification, and Characterization of the hh4-OT and Mutants}

The $\alpha$ - and $\beta$-subunits were initially cloned from C. aurantiacus $\mathrm{J}-10-\mathrm{fl}$ genomic DNA and inserted individually into pBluescript expression vectors. A dicistronic gene for the hh4-OT was then constructed by cloning the $\beta$-subunit into the pBluescript vector containing the $\alpha$ subunit. The five hh4-OT mutants were constructed using the dicistronic pBluescript construct. Finally, a high expression pET system was constructed by amplifying the dicistronic region from pBluescript (using the PCR) and inserting the construct in a pET24a vector at the $\mathrm{XbaI}$ and $\mathrm{XhoI}$ restriction sites.

The recombinant hh4-OT and the five mutants ( $\alpha$ R12A, $\alpha \mathrm{R} 40 \mathrm{~A}, \beta \mathrm{P} 1 \mathrm{~A}, \beta \mathrm{R} 11 \mathrm{~A}$ and $\beta \mathrm{R} 39 \mathrm{~A})$ were purified in a three-step protocol (heat treatment, anion exchange and gel-filtration chromatography). Typically, this procedure yielded $\sim 3-4 \mathrm{mg}$ of homogeneous protein (as assessed by SDS-PAGE) per liter of cell culture. The individual subunits (when expressed, purified separately, subjected to urea treatment and rapid folding) did not have detectable activity (using 1), but a mixture of subunits showed activity (data not shown). These observations indicate that the fully functional enzyme requires both subunits. The crystallography studies were carried out using the hh4-OT produced from the pET24a vector. All other experiments were carried out using hh4-OT (or the hh4-OT mutants) produced from the pBluescript construct.

The purified proteins were analyzed by electrospray ionization mass spectrometry (ESIMS). The samples generate two major signals in the mass spectrometer. The $\alpha$-subunit of wild type has a mass of 7,730 Da, which corresponds to an expected 72-amino acid product with a calculated mass of 7,732 $\mathrm{Da}$. The $\beta$-subunit of wild type has a mass of 7,963 Da, which is $133 \mathrm{Da}$ less than the calculated mass of $8096 \mathrm{Da}$ (for a 73 -amino acid product). The combined observations indicate that the $\beta$-subunit has undergone a post-translational modification to remove the initiating methionine whereas the $\alpha$-subunit has not. The $\alpha$ - and $\beta$-subunits of the mutants show the same pattern (data provided in the Supporting Information). The initiating methionine is removed by a methionyl aminopeptidase, and the removal is correlated with the amino acid in the second position (12). Accordingly, in $E$. coli, a proline or alanine in position 2 (as seen in the $\beta$-subunit) results in a high likelihood of removal. However, if the second position is occupied by a leucine (as seen in the $\alpha$ subunit), the likelihood of removal is very low (12).

\section{Kinetic Characterization of Heterohexamer 4-OT}

The kinetic parameters for the hh4-OT were determined using 2-hydroxymuconate (1) and phenylenolpyruvate (3), and compared to those measured for the homohexamer 4-OT from $P$. putida (Tables 2 and 3). For both substrates, the $K_{\mathrm{m}}$ values are comparable whereas the $k_{\text {cat }}$ values for the homohexamer 4-OT are slightly higher (1.3- and 6-fold higher using 1 and 3 , respectively) than those measured for the hh4-OT. The higher $k_{\text {cat }}$ values are reflected in higher $k_{\mathrm{cat}} / K_{\mathrm{m}}$ values observed for the homohexamer 4-OT. The higher $k_{\text {cat }}$ values may be due to the fact that the hh4-OT is a thermophilic enzyme and is not operating at its optimum temperature.

The hh4-OT was also incubated separately with trans- and cis-3-chloroacrylic acid for 2 weeks. There was no change in the $\lambda_{\max }$ at $224 \mathrm{~nm}$ for either compound. Using this spectrophotometric assay, the hh4-OT does not appear to have low level dehalogenase activity. The absence of activity (and low extinction coefficient at $224 \mathrm{~nm}$ ) prompted us to monitor an incubation mixture containing hh4-OT and $\mathbf{5}$ (Scheme 2) over a much longer time span by ${ }^{1} \mathrm{H}$ NMR spectroscopy. After 7 weeks, there was no spectral evidence for malonate semialdehyde (6), its hydrate, acetaldehyde, 7, (resulting from non-enzymatic decarboxylation of $\mathbf{6}$ ), or the hydrate of acetaldehyde ${ }^{4}$. (The enzyme still retains tautomerase 
activity using 1.) In contrast, $\sim 74 \%$ of compound 5 is converted to acetaldehyde and its hydrate in the presence of 4-OT (using about twice the amount of enzyme, $0.6 \mathrm{mg}$ ) in less than 6 days (22). Hence, there is no evidence for a low level CaaD activity comparable to that of 4-OT in the hh4-OT.

\section{Kinetic Characterization of the hh4-OT Mutants}

The importance of five residues ( $\alpha$ Arg- $12^{5}, \alpha$ Arg- $40, \beta$ Pro- $1, \beta$ Arg- 11 and $\beta$ Arg- 39 ) to the hh4-OT activity was investigated by constructing the alanine mutants at each position and measuring the kinetic parameters using $\mathbf{1}$ and $\mathbf{3}$ (Tables 2 and 3). The data show that replacing $\alpha$ Arg-12, $\alpha$ Arg- 40 , or $\beta$ Pro- 1 with an alanine has significant effects on $k_{\text {cat }}$ (using 1) with 70 -fold $(\alpha \mathrm{R} 12 \mathrm{~A}), 46$-fold $(\alpha \mathrm{R} 40 \mathrm{~A})$, and 83 -fold $(\beta \mathrm{P} 1 \mathrm{~A})$ decreases being observed. There are increases in $K_{\mathrm{m}}$ for the $\alpha \mathrm{R} 12 \mathrm{~A}$ and $\alpha \mathrm{R} 40 \mathrm{~A}$ mutants (15- and 5-fold, respectively) and a small decrease in $K_{\mathrm{m}}$ for the $\beta \mathrm{P} 1 \mathrm{~A}$ mutant (4-fold). As a result, there are 1023- 226-, and 20-fold decreases in $k_{\text {cat }} / K_{\mathrm{m}}$ for the $\alpha \mathrm{R} 12 \mathrm{~A}, \alpha \mathrm{R} 40 \mathrm{~A}$, and $\beta \mathrm{P} 1 \mathrm{~A}$ mutants, respectively. In contrast, replacing $\beta A$ rg-39 with an alanine has a small effect (4-fold decrease in $k_{\text {cat }}$, 2-fold increase in $K_{\mathrm{m}}$, and an 8-fold decrease in $k_{\mathrm{cat}} / K{ }_{-\mathrm{m}}$ ) and changing $\beta$ Arg-11 to an alanine has a negligible effect on the kinetic parameters. These results show that like 4-OT, two arginine residues ( $\alpha$ Arg- 12 and $\alpha$ Arg- 40 ) and the amino-terminal proline ( $\beta$ Pro- 1$)$ are required for the 1,5-enol-keto tautomerase activity using $\mathbf{1}$.

With 3, significant effects on the kinetic parameters are observed only for the $\alpha \mathrm{R} 12 \mathrm{~A}$ and $\beta P 1 A$ mutants. Replacing $\alpha$ Arg- 12 or $\beta$ Pro- 1 with an alanine reduces $k_{\text {cat }} 22$-fold and 65 fold, respectively. The $\alpha \mathrm{R} 12 \mathrm{~A}$ shows little change in $K_{\mathrm{m}}$ and the $\beta \mathrm{P} 1 \mathrm{~A}$ mutant shows a 2fold decrease. The values of $k_{\text {cat }} / K_{\mathrm{m}}$ decrease 26-fold ( $\left.\alpha \mathrm{R} 12 \mathrm{~A}\right)$ and 34 -fold ( $\left.\beta \mathrm{P} 1 \mathrm{~A}\right)$. There is a small increase in $k_{\text {cat }}$ for the $\alpha \mathrm{R} 40 \mathrm{~A}$ mutant (3.4-fold) and little change in $K_{\mathrm{m}}$. As a result, the $k_{\text {cat }} / K_{\mathrm{m}}$ increases 2.6-fold. There are smaller changes in the kinetic parameters for the $\beta R 11 A$ and $\beta R 39 A$ mutants. These results show that only $\alpha$ Arg- 12 and $\beta$ Pro- 1 are required for the 1,3-enol-keto tautomerase activity using $\mathbf{3}$.

\section{Crystal Structure of hh4-OT}

The crystal structure of hh4-OT was determined in order to confirm the oligomeric state and to explore the structural implications of the heterohexamer. Crystals of hh4-OT were grown using a precipitant solution of $0.25 \mathrm{M}\left(\mathrm{NH}_{4}\right)_{2} \mathrm{SO}_{4}$ and $4 \%$ PEG 4000 and diffracted to 2.41 $\AA$. The structure was solved in a $\mathrm{P} 3_{1}$ space group using molecular replacement with a search model derived from a homology model of a theoretical hh4-OT based on a heterohexamer $\mathrm{CaaD}$ (1S0Y) scaffold (25), where the H. influenzae homologue (1MWW) and P. sp CF600 4-OT isozyme (1OTF) serve as templates for the $\alpha$ - and $\beta$-subunits, respectively (Table 1 ). The resulting hh4-OT structure is made up of two heterohexamers per asymmetric unit.

Each heterohexamer contains three heterodimer units composed of one $\alpha$-subunit and one $\beta$ subunit in an alternating fashion (Figure 2A). Both subunits have the signature 4-OT superfamily $\beta-\alpha-\beta$ scaffold but the $\alpha$-subunit displays one more $\beta$-sheet (encoded by residues Trp-51, Thr-52, Val-53) than the $\beta$-subunit, which facilitates an $\alpha$-subunit to $\alpha$ subunit interaction (Figure 2B). Structural alignment of residues 2-50 from each subunit of hh4-OT with the $P$. sp. CF600 isozyme (1OTF) monomer resulted in a relatively low average rmsd of $1.5 \AA$. However, alignment of the $\alpha$ - and $\beta$-subunits of hh4-OT (using residues $2-50$ ) has an average rmsd of $5.5 \AA$. The difference in rmsd can be attributed to the

\footnotetext{
${ }^{4}$ The non-enzymatic decarboxylation of malonate semialdehyde (6) yields acetaldehyde. Malonate semialdehyde is not sufficiently stable to accumulate in quantities detectable by ${ }^{1}$ H NMR spectroscopy in the course of the lengthy incubation periods (22).

5 The presence of the initiating methionine in the $\alpha$-subunit increases the sequence number of each residue by one.
} 
preceding and succeeding $\alpha \mathrm{A}^{\prime}$ loops and the last $10 \mathrm{C}$-terminal residues of the selected alignment region (Figure 2C).

\section{The Active Site of hh4-OT}

Two regions (designated "Type I" and "Type II") located at the interfaces of the three heterodimeric units could serve as potential active sites (Figure 2A). The three Type I sites form around $\alpha$ Met- 1 where the $\alpha \mathrm{A} \beta 2$ loop in the $\alpha$-subunit, the $\beta 1^{\prime} \alpha \mathrm{A}^{\prime}$ loop in the $\beta$-subunit, and a $3_{10}$ helix constitute the three sides of this region (Figure $3 \mathrm{~A}$ ). The Type I site pocket is shallow, as it has been partially filled by aMet-1, and contains no arginine side chains. In addition, the $\alpha$ Met- 1 side chain is inserted into a hydrophobic pocket where the hydroxyl group of $\beta$ Thr-52 forms a polar interaction with the sulfur atom of $\alpha$ Met-1. The $\beta$ Thr-52 position is typically occupied by a residue with a bulky hydrophobic side chain such as Phe-50, as seen in the P. sp. CF600 and P. putida mt-2 4-OTs (27). However, the presence of such a residue in the $\beta$-subunit (and, in turn, at the active site) would clash with the side chain of $\alpha$ Met- 1 . The absence of Phe-50 is also one of the factors that facilitates the formation of a homohexamer. The mutagenesis results (above) coupled with these structural observations eliminate the Type I regions as active sites.

The three Type II sites are formed at the other end of the heterodimeric unit interface around $\beta$ Pro-1 (Figure 3B). As with the Type I sites, two of the Type II active site sides are composed of loops, but these loops are contributed from different subunits, that is, the $\alpha \mathrm{A}$ ' $\beta 2$ ' loop in the $\beta$-subunit and the $\beta 1 \alpha \mathrm{A}$ loop in the $\alpha$-subunit. The third side of the Type II active site is composed of the intramonomeric $\alpha$-subunit $\beta 2-\beta 3$ loop instead of a $3_{10}$ helix (Figure 3B). The Type II sites closely resemble the active sites in the $P$. sp. CF600 and $P$. putida mt-2 4-OTs, as seen when overlaying the structures (Figure 3A,C) (27). Within the Type II sites, a positively charged hydrophilic pocket is created by three arginines, $\alpha \mathrm{Arg}-12$, $\alpha$ Arg- 40 , and $\beta$ Arg39, as well as $\beta$ Thr-35. The general hydrophilic nature of this site allows it to be occupied by either one or two sulfates in the crystal structure. The mutagenesis results (above) and the sum of these structural observations identify the three Type II regions as the active sites in the hh4-OT.

In addition to the charged and polar residues in the Type II site, two hydrophobic pockets are created. One of these sites is created by the side chains of $\beta$ Phe-29, $\beta$ Ile-33, and the side chain methyl group of $\beta \mathrm{Thr}-35$. The other pocket is formed by the side chains of $\alpha \operatorname{Trp}-51$ and $\alpha$ Leu- 9 . This second pocket is positioned in front of the prolyl nitrogen of $\beta$ Pro- 1 suggesting that this pocket could reduce the $\mathrm{p} K_{\mathrm{a}}$ of $\beta$ Pro- 1 to that observed in the $P$. putida mt-2 4-OT ( 6.4) (7).

\section{Thermostability of hh4-OT and 4-OT}

Dynamic scanning calorimetry (DSC) was used to determine the melting temperatures $\left(\mathrm{T}_{\mathrm{m}}\right)$ of the hh4-OT and the homohexamer P. putida mt-2 4-OT (Figure 4A). The heat capacity for both samples was measured from $10^{\circ} \mathrm{C}$ to $125^{\circ} \mathrm{C}$ at 28 psi. Corrected for buffer effects, the $\mathrm{T}_{\mathrm{m}}$ of the homohexamer $P$. putida $\mathrm{mt}-2$ 4-OT was found to be $78.8^{\circ} \mathrm{C}$, whereas the $\mathrm{T}_{\mathrm{m}}$ of the heterohexamer C. aurantiacus $4-\mathrm{OT}$ was $108.8^{\circ} \mathrm{C}$ (Figure $4 \mathrm{~A}$ ). The observance of only one peak for the hh4-OT suggests that the hexameric, dimeric, and secondary structure denatured at approximately the same temperature with no distinction between the $\alpha-$ and $\beta-$ subunits. The higher $\mathrm{T}_{\mathrm{m}}$ for the hh4-OT is likely a characteristic required for its stability in the thermophilic environment, and there is structural evidence that may explain the higher thermostability of the hh4-OT. The interactions between the $\alpha$-and $\beta$-subunits of the hh4-OT are markedly more stable than those found in the homohexamer 4-OT. Specifically, these interactions are found in the core of the protein, where hh4-OT exhibits a unique set of three inter-dimer salt bridges between the $\alpha$ and $\beta$ subunits, involving the residues $\beta$ Glu- 4 and 
$\alpha$ Arg- 5 of each dimer. These salt bridges form a core for a network of hydrogen bonds involving the side chains of $\alpha \mathrm{Gln}-45, \alpha \mathrm{Thr}-7$ and $\alpha \mathrm{Gln}-44$ (Figure 4B). Salt bridges have been shown previously to contribute significantly to the thermostability of an enzyme, both on the surface and in the protein core $(29,30)$. These salt bridges also prohibit the formation of homohexamers composed of all $\alpha$ - or $\beta$-subunits. Such an arrangement would result in unfavorable electrostatic interactions between similarly negatively or positively charged amino acids, depending on the subunit. In contrast to hh4-OT's salt-bridge core, the homohexamer 4-OT from $P$. putida $\mathrm{mt}-2$ relies simply on water-mediated polar interactions between residues Thr-43, His-6, and Gln-4 (Figure 4C). The lack of inter-subunit salt bridges in homohexamer 4-OT may be one factor that could impair its stability in a thermophilic environment.

\section{DISCUSSION}

The homohexamer 4-OT from $P$. putida $\mathrm{mt}-2$ and $P$. $s p$. CF600 has been extensively studied $(4,5,7,13,14,27,31-37)$. The results of these studies identified key mechanistic and structural elements, delineated their roles, and produced a working hypothesis for the 4-OT mechanism (Scheme 3). In this mechanism, Pro-1 is a general base that abstracts the 2hydroxyl proton (of $\mathbf{1}$ ) for delivery to the $\mathrm{C}-5$ position with a high degree of stereoselectivity (31-33). [In $\mathrm{D}_{2} \mathrm{O}$, the (5S)-isomer of [5-D]2 is produced (31)]. Pro-1 can function as a general base because the prolyl nitrogen has a $\mathrm{p} K_{\mathrm{a}}$ of $\sim 6.4$ so that it exists largely as the uncharged species at $\mathrm{pH} 7.3$ (33). The side chains of three residues (Leu- 8 ', Met- $45^{\prime}$, and Phe- $\left.50^{\prime}\right)^{6}$ constitute a hydrophobic pocket in front of the prolyl nitrogen and as such are likely the major groups responsible for the lowered $\mathrm{p} K_{\mathrm{a}}$ of Pro-1 (37). In accord with this observation, changing Phe-50 to an alanine increases the $\mathrm{p} K_{\mathrm{a}}$ of the prolyl nitrogen to 7.3, which is attributed to the increased solvent accessibility around Pro-1 (37). The remaining key catalytic residues are Arg-11 and Arg-39 (14,35,36). Arg-39 is proposed to interact with the 2-hydroxyl group (of $\mathbf{1}$ ) and a C-1 carboxylate oxygen, and has primarily a catalytic role. Arg-11 is proposed to interact with the C-6 carboxylate group in a bidentate fashion, which binds substrate and draws electron density away from $\mathrm{C}-5$, thereby creating a partial positive charge at this position to facilitate protonation.

The structural homology, the positional conservation of key groups, and mutagenic results suggest that the hh4-OT mechanism parallels that of 4-OT. Accordingly, $\beta$ Pro- 1 functions as the general base and the two arginine residues, $\alpha \mathrm{Arg}-12^{5}$ and $\alpha \mathrm{Arg}-40$, interact respectively with the C-6 and C-1 carboxylate groups. $\alpha$ Arg- 40 may also interact with the 2-hydroxyl group and stabilize the developing carbanion charge after its deprotonation. The $\mathrm{p} K_{\mathrm{a}}$ of the $\beta$ Pro-1 is likely comparable to that of Pro-1 in 4-OT because of the hydrophobic pocket formed by $\alpha$ Leu- 9 and $\alpha$ Trp- 51 (comparable to Leu- 8 and Phe-50 in the P. putida mt- 2 4OT).

The results of the mutagenesis experiments on $\beta$ Pro- $1, \alpha$ Arg- 12 and $\alpha$ Arg- 40 are in accord with the proposed mechanism and parallel the results obtained for 4-OT. Thus, changing the rigid secondary amine (i.e., $\beta$ Pro-1) to a more flexible primary amine (i.e., $\beta$ Ala-1) primarily affects $k_{\text {cat }}$ and $k_{\text {cat }} / K_{\mathrm{m}}$. This observation suggests that the mutation affects reaction chemistry, release of product, or both (34). The decreased activity could be due to a decrease in basicity coupled with a sub-optimal positioning of the catalytic base due to the increased flexibility of the primary amine. The small decrease in $K_{\mathrm{m}}$ for the $\beta \mathrm{P} 1 \mathrm{~A}$ mutant may be due to the removal of bulk (e.g., the 5-membered ring system), making binding more favorable (if $K_{\mathrm{m}}$ is a reflection of binding). It is not unexpected to see activity for the $\beta \mathrm{P} 1 \mathrm{~A}$ mutant because $\beta$ Ala-1 still has an amino terminal group that can function as a base. Both the P1G

\footnotetext{
${ }^{6}$ The primed residues refer to different subunits within the 4-OT homohexamer.
} 
and P1A mutants of 4-OT retain a significant amount of activity (34). Changing $\alpha$ Arg-12 to an alanine affects both $K_{\mathrm{m}}$ and $k_{\mathrm{cat}}$, consistent with its role in binding (C-6) and catalysis (drawing electron density away from C-5) $(7,35,36)$. Changing $\alpha$ Arg- 40 to an alanine affects both $K_{\mathrm{m}}$ and $k_{\text {cat }}$, but the effect on $K_{\mathrm{m}}$ is not as severe as that seen for the $\alpha \mathrm{R} 12 \mathrm{~A}$ mutant $(35,36)$. Hence, the function of $\alpha \mathrm{Arg}-40$ is predominantly catalytic ${ }^{7}$. Both results are consistent with those observed for 4-OT mutants.

The behavior of hh4-OT and its mutants with the non-physiological substrate $\mathbf{3}$, a monoacid, implicates $\beta$ Pro- 1 and $\alpha$ Arg- 12 in catalysis. The reduced activity of the $\beta \mathrm{P} 1 \mathrm{~A}$ mutant can again be ascribed to a decrease in basicity along with a sub-optimal positioning of the catalytic base, as discussed above. Changing $\alpha$ Arg- 12 to an alanine affects $k_{\mathrm{cat}}$, but not $K_{\mathrm{m}}$. This observation argues against a binding role for $\alpha$ Arg- 12 and instead suggests a catalytic role. The absence of the positively charged arginine at this position could destabilize the developing carbanionic character of the intermediate after deprotonation of the 2-hydroxyl group. The mutation may also affect the $\mathrm{p} K_{\mathrm{a}}$ of $\beta$ Pro- 1 or the positioning of a catalytic group or groups. The other arginine residues ( $\alpha$ Arg-40, $\beta$ Arg-11 and $\beta$ Arg-39) do not appear to be involved in binding or in catalysis.

The results of modeling studies are consistent with the proposed orientations in the active site (Figure 5). Modeling 1 into the active site shows the respective interactions of the C-6 carboxylate and C- 1 carboxylate groups with $\alpha$ Arg- 12 and $\alpha$ Arg- 40 (Figure 5A). $\beta$ Pro- 1 is proximal to the 2-hydroxyl proton. Modeling 3 into the active site shows the proximity of the $\mathrm{C}-1$ carboxylate group to $\alpha \mathrm{Arg}-12$ (Figure $5 \mathrm{~B}$ ). Again, $\beta$ Pro- 1 is near the 2-hydroxyl proton (of 3). Candidates that might bind the $\mathrm{C}-1$ carboxylate group were not identified, but the interaction between the phenyl ring of $\mathbf{3}$ and $\alpha$ Trp- 51 is one possible binding determinant.

Stereochemical experiments could shed further light on the binding of $\mathbf{3}$. For example, if the monoacid 3 binds in a single orientation (with the $\mathrm{C}-1$ carboxylate end pointing toward $\alpha$ Arg-12), then a high degree of stereoselectivity is expected (at C-3 of $\mathbf{4}$ ) when the reaction is carried out in $\mathrm{D}_{2} \mathrm{O}$. If compound $\mathbf{3}$ binds in two orientations (the $\mathrm{C}-1$ carboxylate end pointing toward $\alpha$ Arg- 12 or the $C-1$ carboxylate end pointing toward $\alpha A r g-40$ ), then a mixture of stereoisomers is expected.

The characterization of the two tautomerase sequences of $C$. aurantiacus $\mathrm{J}-10-\mathrm{fl}$ and the conservation of key mechanistic and structural residues suggest that the gene products in the four other organisms (in Figure 1) will also form functional heterohexamers with 1,5- and 1,3-keto-enol tautomerase activities using $\mathbf{1}$ and $\mathbf{3}$, respectively. These hh4-OTs are likely composed of three heterodimers where each dimer consists of an $\alpha$ - and $\beta$-subunit. The heterohexamer structure presumably confers thermostability. Finally, $\beta$ Pro- $1, \alpha$ Arg- 12 and $\beta$ Arg- 40 are present in these sequences and have analogous roles to those of the $C$. aurantiacus hh4-OT.

Thus far, the only other characterized heterohexamer in the tautomerase superfamily is CaaD, which catalyzes the hydrolytic dehalogenation of trans-3-chloroacrylate $(\mathbf{5}$, Scheme 2) $(17,26)$. Like the hh4- OT, CaaD is a trimer of dimers where the three active sites are composed of residues from $\alpha$ - and $\beta$-subunits (26). Both subunits of CaaD have an amino terminal proline but only the $\beta$ Pro- 1 is catalytic. Accordingly, the active site in one heterodimer is composed of $\beta$ Pro- $1, \alpha$ Arg- $8, \alpha$ Arg-11, and $\alpha$ Glu-52 (Scheme 4$)$. In the proposed mechanism, the arginine pair interacts with the carboxylate group of substrate to

\footnotetext{
${ }^{7}$ The $\mathrm{p} K_{\mathrm{a}}$ of Pro-1 in the R39Q mutant of 4-OT is 7.1 (36). A similar $\mathrm{p} K_{\mathrm{a}}$ for Pro- 1 in the $\alpha \mathrm{R} 40 \mathrm{~A}$ mutant of hh4-OT could partially contribute to its decrease in activity.
} 
bind and polarize the substrate, and $\alpha \mathrm{Glu}-52$ activates water for addition at C-3. These actions produce the enediolate species $\mathbf{8}$, which can undergo two fates (Route $\mathrm{A}$ or $\mathrm{B}$ ) $(26,38)$. In Route $A, \beta$ Pro- 1 provides a proton at $C-2$ and the resulting species 9 collapses to $\mathbf{6}$ by the direct expulsion of the chloride $(26,38)$. In Route B, rearrangement of $\mathbf{8}$ with the elimination of chloride (i.e., an $\alpha, \beta$-elimination) yields enol 10, which can tautomerize to 6 $(26,38)$. Again, $\beta$ Pro-1 may provide a proton at C-2.

The P. putida mt-2 4-OT has a low level CaaD activity (as well as a low level cis-CaaD activity) $(22)^{8}$. Mutagenic analysis implicated Pro- 1 as a critical residue for the $\mathrm{CaaD}$ activity, but not Arg-11 ${ }^{9}$. Hence, it was proposed that Arg-11 or Arg-39 interacted with the C- 1 carboxylate group of the substrate, thereby polarizing the $\alpha, \beta$-unsaturated acid and creating a partial positive charge at C-3 (Scheme 5). Water could then attack at C-3 with (or without) the assistance of Pro-1 (22). Further support for this mechanism came from the observation that changing Leu-8 in 4-OT to an arginine enhanced the low level CaaD activity (14). The additional arginine is proposed to assist in polarization of the substrate and perhaps result in a preferred orientation of substrate where the interaction with the two arginines is now favored over the interaction with a single arginine, Arg-39.

In contrast, hh4-OT does not have a low level CaaD activity. This observation is particularly curious because of the striking similarities in the active sites including the presence of the key residues associated with the low level CaaD activity of 4-OT (i.e., $\beta$ Pro-1 and $\alpha$ Arg-12). One possible explanation for the absent activity may reside with the presence of $\alpha \operatorname{Trp}-51$ instead of a phenylalanine, found in both $\mathrm{CaaD}(\alpha \mathrm{Phe}-50)$ and 4-OT (Phe-50). A comparison of the active sites suggests that the extra bulk of this residue in hh4-OT fills the cavity and may exclude an appropriately placed water molecule or interfere with the action of Pro- 1 . This observation implies that the other hh4-OTs identified in this study (i.e., Figure 1) will not have a low level CaaD activity because tryptophan is conserved at this position.

Although Phe-50 is critical for the tautomerase activity of 4-OT, this is the first indication that it may also be critical for the low level CaaD activity (of 4-OT). Changing the phenylalanine to a tryptophan in 4-OT might diminish or eliminate the activity whereas changing the tryptophan to a phenylalanine might introduce the activity in hh4-OT. Moreover, the newly introduced activity could be enhanced by the $\alpha \mathrm{L} 9 \mathrm{R}$ mutation (comparable to the L8R mutation of 4-OT). The effects of these mutations on the parent tautomerase activity are not known.

If the $\alpha \mathrm{W} 51 \mathrm{~F}$ mutant of hh4-OT has measurable CaaD activity that is enhanced by additional mutagenesis, it would further support a scenario for the evolution of new enzymatic activities demonstrated by Gerlt and colleagues $(39,40)$. It was found that a single mutation in L-Ala-D,L-Glu epimerase (AEE), an enolase superfamily member, introduced a low level activity of another superfamily member, $o$-succinylbenzoate synthase (OSBS). Three additional mutations to the now functionally promiscuous construct produced an enzyme with a rate acceleration that was only two orders of magnitude less than that of the natural $E$. coli OSBS. The improvement in activity came about by an increase in substrate specificity. This sequence of events likely mimics (on some level) nature's process to generate new enzymatic activities, that is, a promiscuous enzyme is first created and then enhanced by a small number of mutations $(39,40)$. The hh4-OT may likewise develop into an interesting model system to explore the evolution of CaaD activity in the tautomerase superfamily. The appropriate experiments are underway.

\footnotetext{
${ }^{8}$ The $P$. sp. CF600 4-OT has not been examined for low level dehalogenase activities.

${ }^{9}$ Changing Arg-11 to an alanine increases the CaaD activity of 4-OT (22). Presumably Arg-39 interacts with the carboxylate group of substrate in the R11A-4-OT.
} 


\section{Supplementary Material}

Refer to Web version on PubMed Central for supplementary material.

\section{Acknowledgments}

We thank Dr. Michael T. Madigan for the generous gift of Chloroflexus aurantiacus J-10-fl. The cells were grown in the laboratory of Dr. David Graham, Department of Chemistry \& Biochemistry University of Texas at Austin. Supporting institutions of the SER-CAT 22-BM beamline at the Advanced Photon Source, Argonne National Laboratory, can be found at www.ser-cat.org/members.html.

\section{References}

1. Harayama S, Lehrbach PL, Timmis KN. Transposon mutagenesis analysis of meta-cleavage pathway operon genes of the TOL plasmid of Pseudomonas putida mt-2. J Bacteriol 1984;160:251255. [PubMed: 6090417]

2. Harayama S, Rekik M, Ngai K-L, Ornston LN. Physically associated enzymes produce and metabolize 2-hydroxy-2,4-dienoate, a chemically unstable intermediate formed in catechol metabolism via meta cleavage in Pseudomonas putida. J Bacteriol 1989;171:6251-6258. [PubMed: 2681159]

3. Dagley, S. Pathways for the utilization of organic growth substrates. In: Ornston, LN.; Sokatch, JR., editors. The Bacteria: A Treatise on Structure and Function. Academic Press; New York: 1978. p. 305-388.

4. Whitman CP, Aird BA, Gillespie WR, Stolowich NJ. Chemical and enzymatic ketonization of 2hydroxymuconate, a conjugated enol. J Am Chem Soc 1991;113:3154-3162.

5. Wang SC, Johnson WH Jr, Czerwinski RM, Stamps SL, Whitman CP. Kinetic and stereochemical analysis of YwhB, a 4-oxalocrotonate tautomerase homologue in Bacillus subtilis: mechanistic implications for the YwhB- and 4-oxalocrotonate tautomerase-catalyzed reactions. Biochemistry 2007;46:11919-11929. [PubMed: 17902707]

6. Murzin AG. Structural classification of proteins: new superfamilies. Curr Opin Struct Biol 1996;6:386-394. [PubMed: 8804825]

7. Whitman CP. The 4-oxalocrotonate tautomerase family of enzymes: how nature makes new enzymes using a $\beta-\alpha-\beta$ structural motif. Arch Biochem Biophys 2002;402:1-13. [PubMed: 12051677]

8. Poelarends GJ, Whitman CP. Evolution of enzymatic activity in the tautomerase superfamily: mechanistic and structural studies of the 1,3-dichloropropene catabolic enzymes. Bioorg Chem 2004;32:376-392. [PubMed: 15381403]

9. de Jong RM, Bazzacco P, Poelarends GJ, JOHNSON WH JR, Kim Y-J, Burks EA, Serrano H, Thunnissen A-MWH, Whitman CP, Dijkstra BW. Crystal structures of native and inactivated cis-3chloroacrylic acid dehalogenase: structural basis for substrate specificity and inactivation by $(R)-$ oxirane-2-carboxylate. J Biol Chem 2007;282:2440-2449. [PubMed: 17121835]

10. Almrud JJ, Poelarends GJ, Johnson WH Jr, Serrano H, Hackert ML, Whitman CP. Crystal structures of the wild-type, P1A mutant, and inactivated malonate semialdehyde decarboxylase: a structural basis for the decarboxylase and hydratase activities. Biochemistry 2005;44:14818 14827. [PubMed: 16274229]

11. Almrud JJ, Kern AD, Wang SC, Czerwinski RM, Johnson WH Jr, Murzin AG, Hackert ML, Whitman CP. The crystal structure of YdcE, a 4-oxalocrotonate tautomerase homologue from Escherichia coli, confirms the structural basis for oligomer diversity. Biochemistry 2002;41:12010-12024. [PubMed: 12356301]

12. Hirel PH, Schmitter JM, Dessen P, Fayat G, Blanquet S. Extent of N-terminal methionine excision from Escherichia coli proteins is governed by the side-chain length of the penultimate amino acid. Proc Natl Acad Sci USA 1989;86:8247-8251. [PubMed: 2682640]

13. Chen LH, Kenyon GL, Curtin F, Harayama S, Bembenek ME, Hajipour G, Whitman CP. 4Oxalocrotonate tautomerase, an enzyme composed of 62 amino acid residues per monomer. J Biol Chem 1992;267:17716-17721. [PubMed: 1339435] 
14. Poelarends GJ, Almrud JJ, Serrano H, Darty JE, Johnson WH Jr, Hackert ML, Whitman CP. Evolution of enzymatic activity in the tautomerase superfamily: mechanistic and structural consequences of the L8R mutation in 4-oxalocrotonate tautomerase. Biochemistry 2006;45:7700 7708. [PubMed: 16784221]

15. Sambrook, J.; Fritsch, EF.; Maniatis, T. Molecular Cloning: A Laboratory Manual. 2. Cold Spring Harbor Laboratory; Cold Spring Harbor, NY: 1989.

16. Nübel U, Bateson MM, Madigan MT, Kühl M, Ward DM. Diversity and distribution in hypersaline microbial mats of bacteria related to Chloroflexus spp. Appl Environ Microb 2001;67:4365-4371.

17. Wang SC, Person MD, Johnson WH Jr, Whitman CP. Reactions of trans-3-chloroacrylic acid dehalogenase with acetylene substrates: consequences of and evidence for a hydration reaction. Biochemistry 2003;42:8762-8773. [PubMed: 12873137]

18. Waddell WJ. A simple ultraviolet spectrophotometric method for the determination of protein. J Lab Clin Med 1956;48:311-314. [PubMed: 13346201]

19. Laemmli UK. Cleavage of structural proteins during the assembly of the head of bacteriophage T4. Nature 1970;227:680-685. [PubMed: 5432063]

20. Pospiech A, Neumann B. A versatile quick-prep of genomic DNA from Gram- positive bacteria. Trends Genet 1995;11:217-218. [PubMed: 7638902]

21. Poelarends GJ, Serrano H, Person MD, Johnson WH Jr, Murzin AG, Whitman CP. Cloning, expression, and characterization of a cis-3-chloroacrylic acid dehalogenase: insights into the mechanistic, structural, and evolutionary relationship between isomer-specific 3-chloroacrylic acid dehalogenases. Biochemistry 2004;43:759-772. [PubMed: 14730981]

22. Wang SC, Johnson WH Jr, Whitman CP. The 4-oxalocrotonate tautomerase- and YwhB-catalyzed hydration of $3 E$-haloacrylates: implications for evolution of new enzymatic activities. $\mathrm{J}$ Am Chem Soc 2003;125:14282-14283. [PubMed: 14624569]

23. Otwinowski Z, Minor W. Processing of x-ray diffraction data collected in oscillation mode. Methods Enzymol 1997;276:307-326.

24. Collaborative Computational Project Number 4. The CCP4 suite: programs for protein crystallography. Acta Crystallogr Sect D: Biol Crystallogr 1994;50:760-763. [PubMed: 15299374]

25. Bates PA, Kelley LA, MacCallum RM, Sternberg MJ. Enhancement of protein modeling by human intervention in applying the automatic programs 3D-JIGSAW and 3D-PSSM. Proteins, Suppl 2001;5:39-46.

26. de Jong RM, Brugman W, Poelarends GJ, Whitman CP, Dijkstra BW. The X-ray structure of trans-3-chloroacrylic acid dehalogenase reveals a novel hydration mechanism in the tautomerase superfamily. J Biol Chem 2004;279:11546-11552. [PubMed: 14701869]

27. Subramanya HS, Roper DI, Dauter Z, Dodson EJ, Davies GJ, Wilson KS, Wigley DB. Enzymatic ketonization of 2-hydroxymuconate: specificity and mechanism investigated by the crystal structures of two isomerases. Biochemistry 1996;35:792-802. [PubMed: 8547259]

28. Emsley P, Cowtan K. Coot: model-building tools for molecular graphics. Acta Crystallogr Sect D: Biol Crystallogr 2004;60:2126-2132. [PubMed: 15572765]

29. Makhatadze GI, Loladze VV, Ermolenko DN, Chen X, Thomas ST. Contribution of surface salt bridges to protein stability: guidelines for protein engineering. J Mol Biol 2003;327:1135-1148. [PubMed: 12662936]

30. Missimer JH, Steinmetz MO, Baron R, Winkler FK, Kammerer RA, Daura X, van Gunsteren WF. Configurational entropy elucidates the role of salt-bridge networks in protein thermostability. Protein Sci 2007;16:1349-1359. [PubMed: 17586770]

31. Whitman CP, Hajipour G, Watson RJ, Johnson WH Jr, Bembenek ME, Stolowich NJ. Stereospecific ketonization of 2-hydroxymuconate by 4-oxalocrotonate tautomerase and 5(carboxymethyl)-2-hydroxymuconate isomerase. J Am Chem Soc 1992;114:10104-10110.

32. Stivers JT, Abeygunawardana C, Mildvan AS, Hajipour G, Whitman CP, Chen LH. Catalytic role of the amino-terminal proline in 4-oxalocrotonate tautomerase: affinity labeling and heteronuclear NMR studies. Biochemistry 1996;35:803-813. [PubMed: 8547260] 
33. Stivers JT, Abeygunawardana Mildvan AS, Hajipour G, Whitman CP. 4- Oxalocrotonate tautomerase: $\mathrm{pH}$ dependences of catalysis and $\mathrm{p} K_{\mathrm{a}}$ values of active site residues. Biochemistry 1996;35:814-823. [PubMed: 8547261]

34. Czerwinski RM, Johnson WH Jr, Whitman CP, Harris TK, Abeygunawardana C, Mildvan AS. Kinetic and structural effects of mutations of the catalytic amino-terminal proline in 4oxalocrotonate tautomerase. Biochemistry 1997;36:14551-14560. [PubMed: 9398173]

35. Harris TK, Czerwinski RM, Johnson WH Jr, Legler PM, Abeygunawardana C, Massiah MA, Stivers JT, Whitman CP, Mildvan AS. Kinetic, stereochemical, and structural effects of mutations of the active site arginine residues in 4-oxalocrotonate tautomerase. Biochemistry 1999;38:1234312357. [PubMed: 10493802]

36. Czerwinski RM, Harris TK, Johnson WH Jr, Legler PM, Stivers JT, Mildvan AS, Whitman CP. Effects of mutations of the active site arginine residues in 4-oxalocrotonate tautomerase on the $\mathrm{p} K_{\mathrm{a}}$ values of active site residues and on the $\mathrm{pH}$ dependence of catalysis. Biochemistry 1999;38:12358-12366. [PubMed: 10493803]

37. Czerwinski RM, Harris TK, Massiah MA, Mildvan AS, Whitman CP. The structural basis for the perturbed $\mathrm{p} K_{\mathrm{a}}$ of the catalytic base in 4-oxalocrotonate tautomerase: kinetic and structural effects of mutations of Phe-50. Biochemistry 2001;40:1984-1995. [PubMed: 11329265]

38. Azurmendi HF, Wang SC, Massiah MA, Poelarends GJ, Whitman CP, Mildvan AS. The roles of active-site residues in the catalytic mechanism of trans-3-chloroacrylic acid dehalogenase: a kinetic, NMR, and mutational analysis. Biochemistry 2004;43:4082-4091. [PubMed: 15065850]

39. Schmidt DMZ, Mundorff EC, Dojka M, Bermudez E, Ness JE, Govindarajan S, Babbitt PC, Minshull J, Gerlt JA. Evolution potential of $(\beta / \alpha)_{8}$-barrels: functional promiscuity produced by single substitutions in the enolase superfamily. Biochemistry 2003;42:8387-8393. [PubMed: 12859183]

40. Vick JE, Schmidt DMZ, Gerlt JA. Evolutionary potential of $(\beta / \alpha)_{8}$-barrels: in vitro enhancement of a "new" reaction in the enolase superfamily. Biochemistry 2005;44:11722-11729. [PubMed: 16128573]

41. Kabsch W, Sander C. Dictionary of protein secondary structure: pattern recognition of hydrogenbonded and geometrical features. Biopolymers 1983;22:2577-2637. [PubMed: 6667333] 

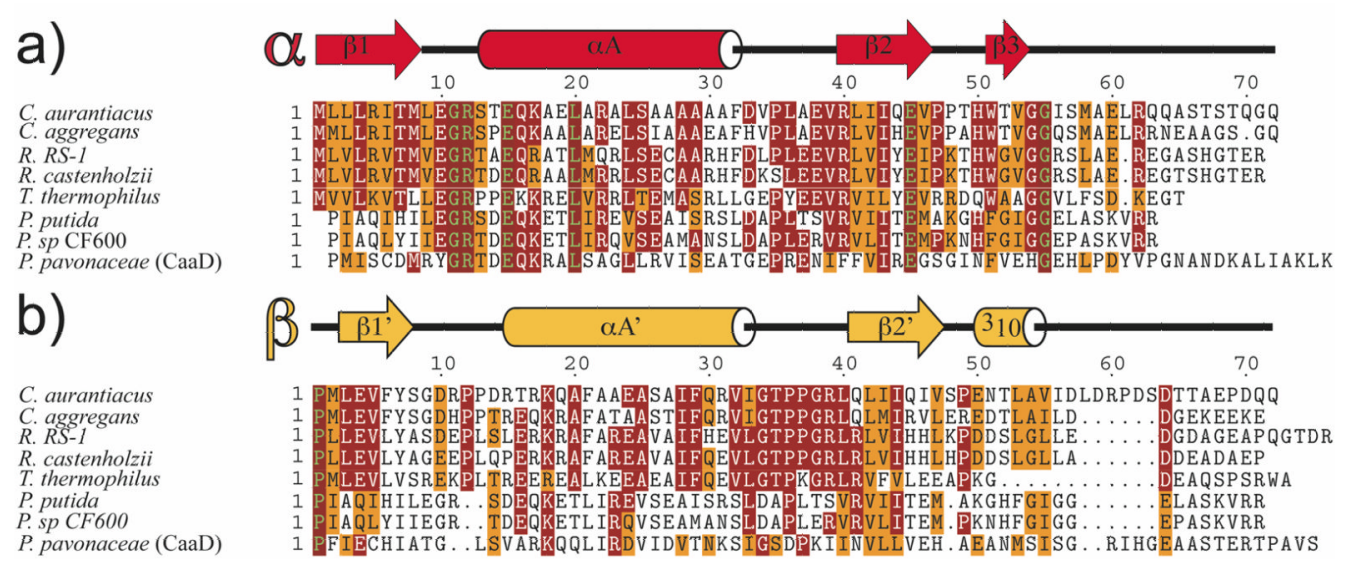

Figure 1.

Sequence alignment of the $\alpha$ - and $\beta$-subunits of the thermophilic hh4-OTs along with the 4OT isozymes from P.putida mt-2 and $P$ sp. CF600 and the $\alpha$ - and $\beta$-subunits of CaaD (from $P$. pavonaceae). The secondary structure elements are shown above each set and were generated by dictionary of protein secondary structure using the $C$. aurantiacus $\mathrm{J}-10-\mathrm{fl}$ hh4OT structure (41). The shading indicates similar (orange), conserved (red), and absolutely conserved (red with green text) residues. (A) The sequences are ordered from the highest to lowest percentage of sequence similarity with the $\alpha$-subunit of $C$. aurantiacus J-10-fl (GI: 163846927) (from top to bottom). Accordingly, the $\alpha$-subunit of $C$. aggregans DSM 9485 (GI:219848927) has 59\% similarity, the $\alpha$-subunit of Roseiflexus sp. RS-1 (GI:148656696) has 58\% similarity, the $\alpha$-subunit of $R$. castenholzii DSM 13941 (GI:156742377) has 57\% similarity, the $\alpha$-subunit of Thermus thermophilus HB8 plasmid (GI:55978425) has 40\% similarity, 4-OT from $P$. putida mt-2 (GI:150974) has 41\% similarity, 4-OT from $P$. $s p$ CF600 (GI:1421033) has 38\% similarity, and the $\alpha$-subunit of CaaD from $P$. pavonaceae (GI:10637969) has 29\% similarity. (B) The sequences are shown in the order of the highest to lowest percentage of sequence similarity with the $\beta$-subunit of $C$. aurantiacus J-10-fl (GI: 163846931) (from top to bottom). Accordingly, the $\beta$-subunit of $C$. aggregans DSM 9485 (GI:219848931) has 70\% similarity, the $\beta$-subunit of $R$. sp. RS-1 (GI:148656700) has 51\% similarity, the $\beta$-subunit of $R$. castenholzii DSM 13941 (GI:156742373) has 50\% similarity, the $\beta$-subunit of $T$. thermophilus HB8 plasmid (GI:55978421*) has 46\% similarity, 4-OT from P. putida mt-2 has $13.9 \%$ similarity **, 4-OT from P. sp CF600 has $15.3 \%$ similarity **, and the $\beta$-subunit of $P$. pavonaceae CaaD (GI:10637970) has $21 \%$ similarity. Alignment and similarity calculation were obtained by using the CLUSTALW, TEXSHADE, BL2SEQ, and ALIGN programs, which can be found at http://workbench.sdsc.edu/. The BL2SEQ settings were Matrix $=$ BLOSUM62. The CLUSTERW settings were Gap Opening Penalty $=11$, Gap Extension Penalty $=1$, and Lambda Ratio $=0.85$. The single asterisk indicates that the reported sequence is missing the initiating methionine and proline. A review of the corresponding gene indicated that the missing amino acids are present. The double asterisk indicates that the ALIGN program was used. 
a)

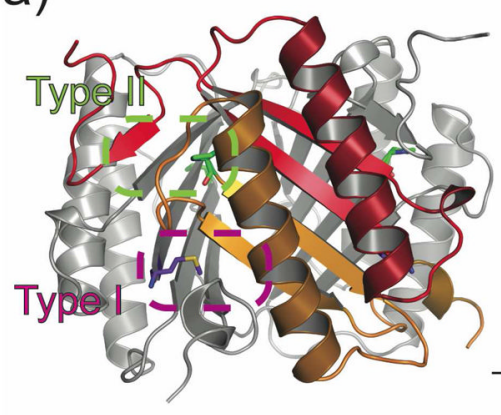

b)

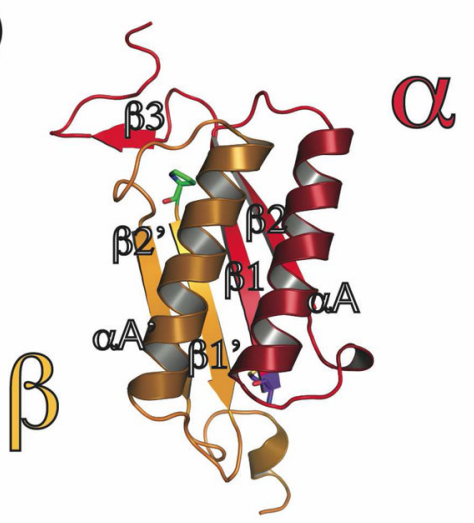

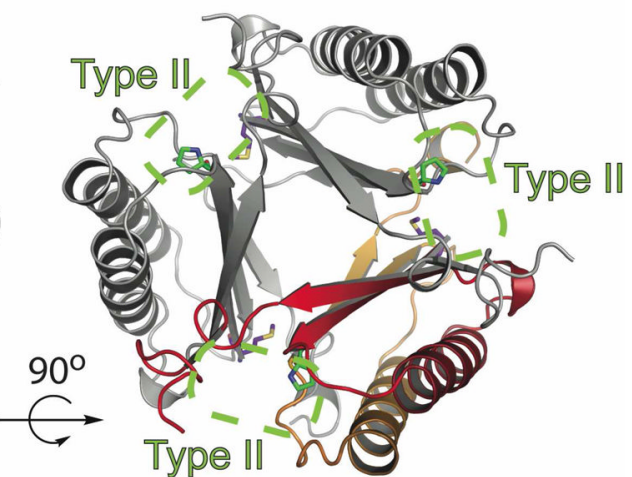

c)

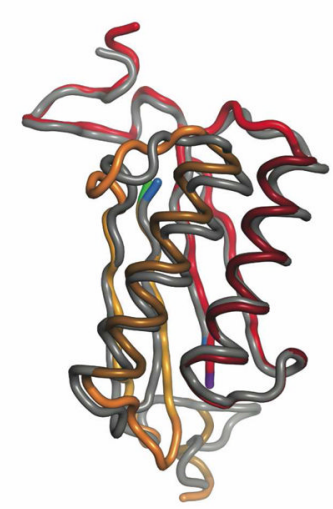

Figure 2.

Structural composition of hh4-OT. (A) Biologically significant unit of hh4-OT viewed from the side and above. The $\alpha$ - and $\beta$-subunits of a heterodimer are shown respectively in red and orange whereas the other two heterodimers are shown in gray. The catalytic $\beta$ Pro- 1 is shown in green and the $\alpha \mathrm{Met}-1$ is shown in purple. Additionally, type I (lavender) and type II (green) active sites are denoted as colored boxed regions superimposed onto hh4-OT. (B) A ribbon diagram of a single heterodimer using the colors defined above. (C) The LSQKAB alignment of a single heterodimer of hh4-OT in the colors (defined above) superimposed on the $P$. $s p$ CF600 4OT (1OTF), shown in gray with the $\mathrm{N}$-terminus in blue. 

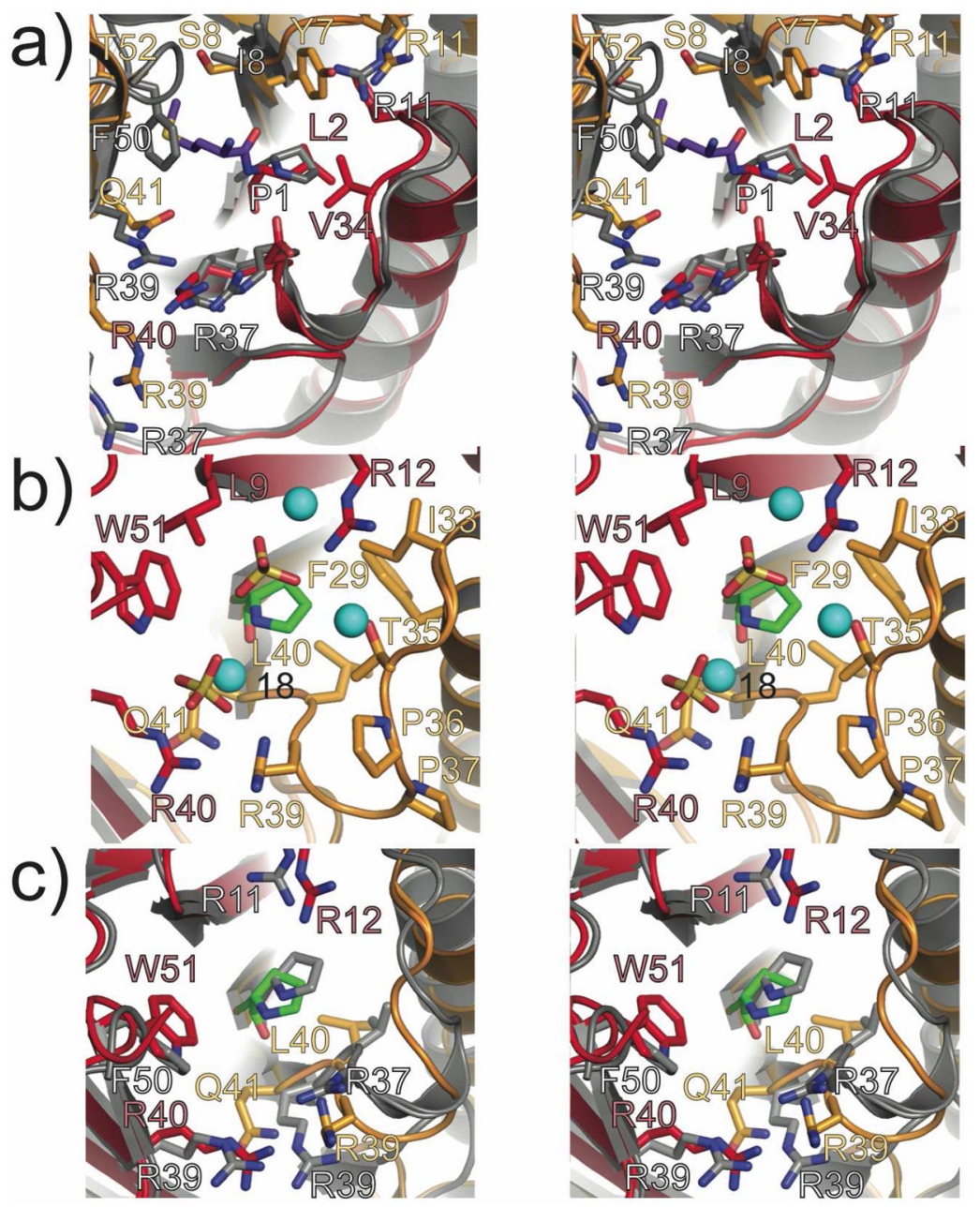

Figure 3.

The active site of the hh4-OT. (A) Divergent stereo view of the hh4-OT non-catalytic Type I site formed by $\alpha$-subunit $\mathrm{E}$ (red) and $\beta$-subunit $\mathrm{D}$ (orange) with $\alpha \mathrm{Met}-1$ in purple. The active site of the $P$. sp CF600 4OT (1OTF) is superimposed in gray. (B) Divergent stereo view of the hh4-OT Type II active site formed by $\alpha$-subunit A (red) and $\beta$-subunit D (orange) with $\beta$ Pro-1 in green. Water molecules are depicted as cyan spheres and sulfate molecules are shown in gold with pink oxygen molecules. (C) Divergent stereo view of hh4-OT Type II active site with $P$. $s p$ CF600 4OT (1OTF) superimposed in gray. 
a)

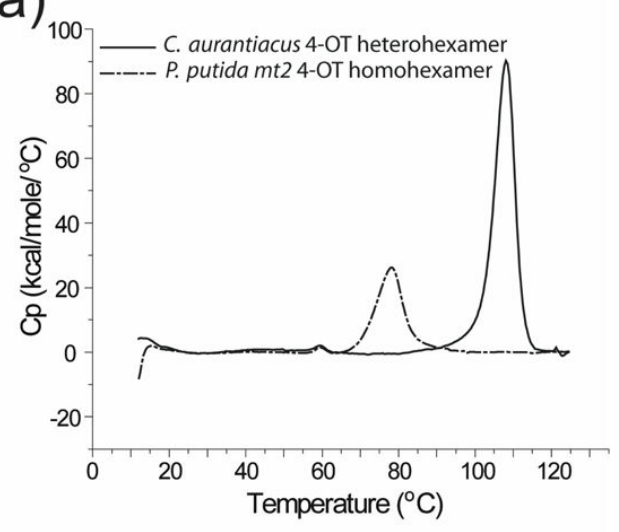

b)
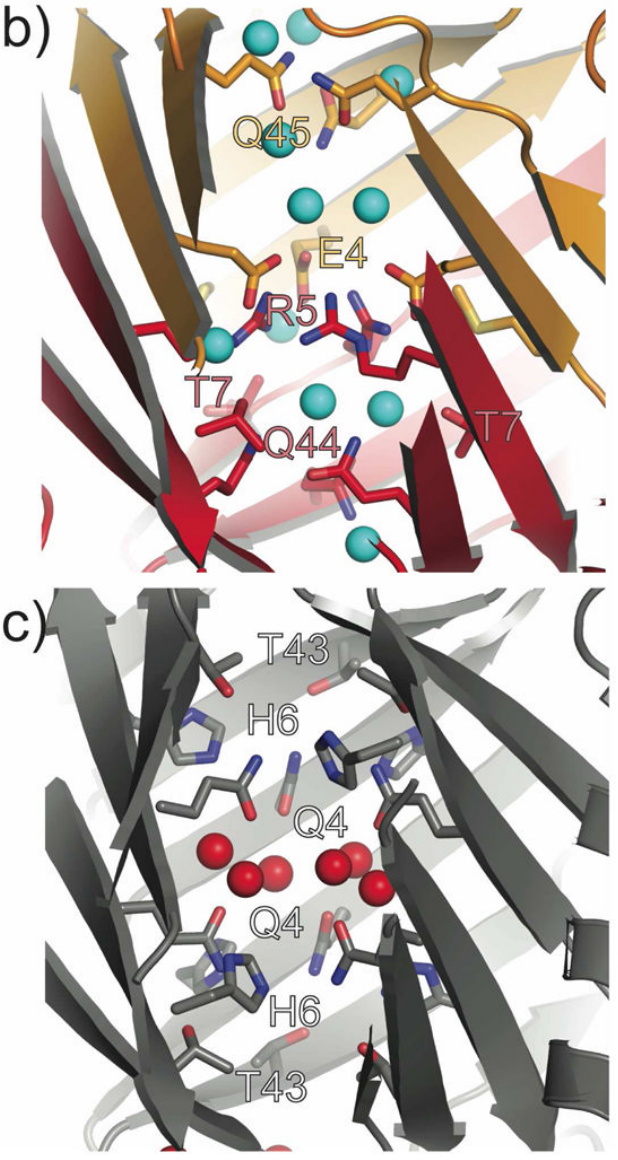

Figure 4.

Thermostability of hh4-OT and 4-OT. (A) Thermal denaturation of the P. putida mt-2 4-OT and hh4-OT at $\mathrm{pH} 7.3$ by differential scanning calorimetry. Curves are derived from the average of 5 DSC scans per protein with the baseline subtracted. (B) Internal cavity of hh4OT. The $\alpha$ - and $\beta$-subunits are shown respectively in red and orange. Water molecules are depicted as cyan spheres. (C) Internal cavity of 4-OT from putida mt-2 (4OTB) aligned as described above in B. Waters are depicted as red spheres. 

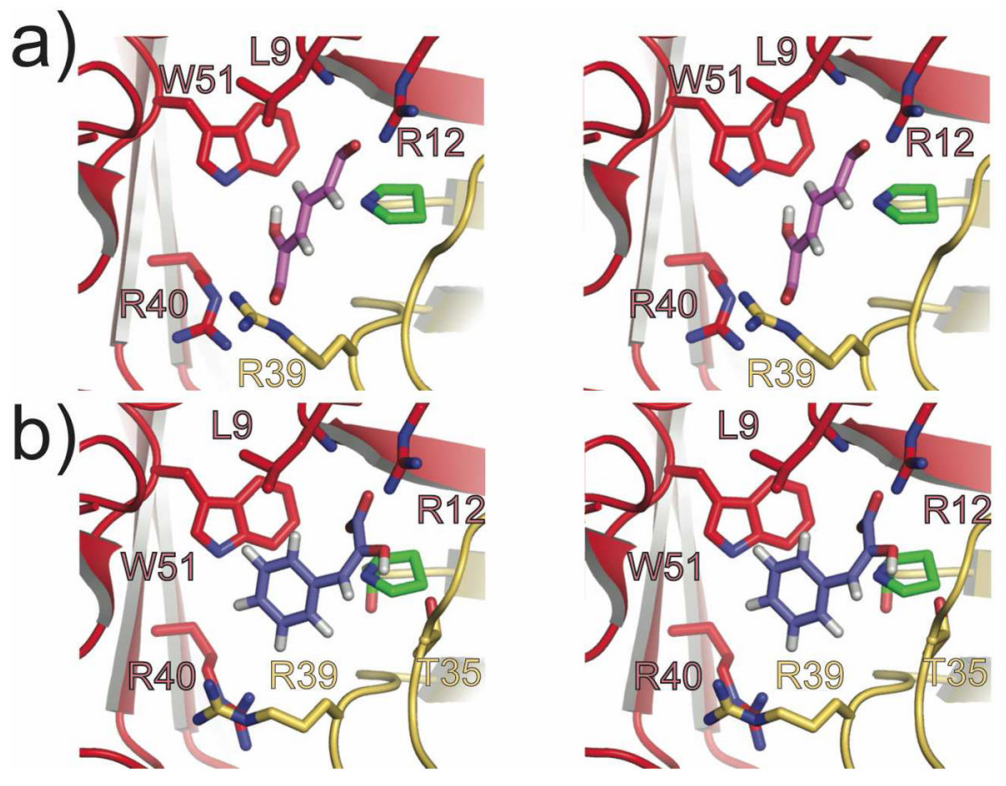

Figure 5.

Comparison of hh4-OT substrate-bound models. (A) Divergent stereo view of the hh4-OT active site (3EJ7) with 2-hydroxymuconate (pink) modeled in the site. The $\beta$-Pro-1 is shown in green, the $\alpha$-subunit $\mathrm{A}$ is shown in red, and the $\beta$-subunit $\mathrm{D}$ is shown in orange. (B) Divergent stereo view of the hh4-OT active site with phenylenolpyruvate (purple) modeled in the site. All other atoms are shown as described in A. 
Burks et al.

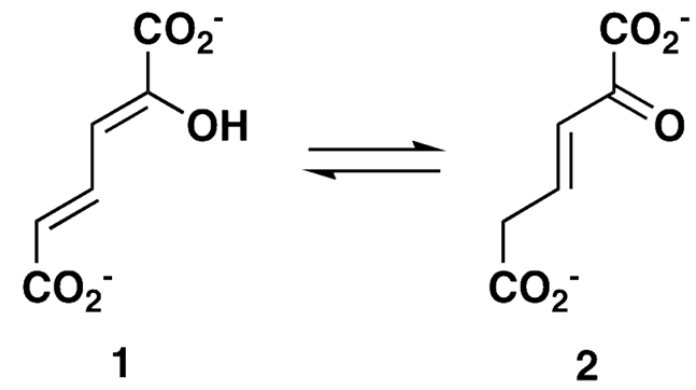

Page 22<smiles></smiles>

Scheme 1. 


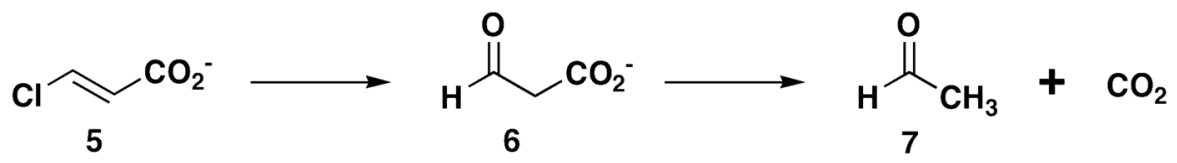

Scheme 2. 


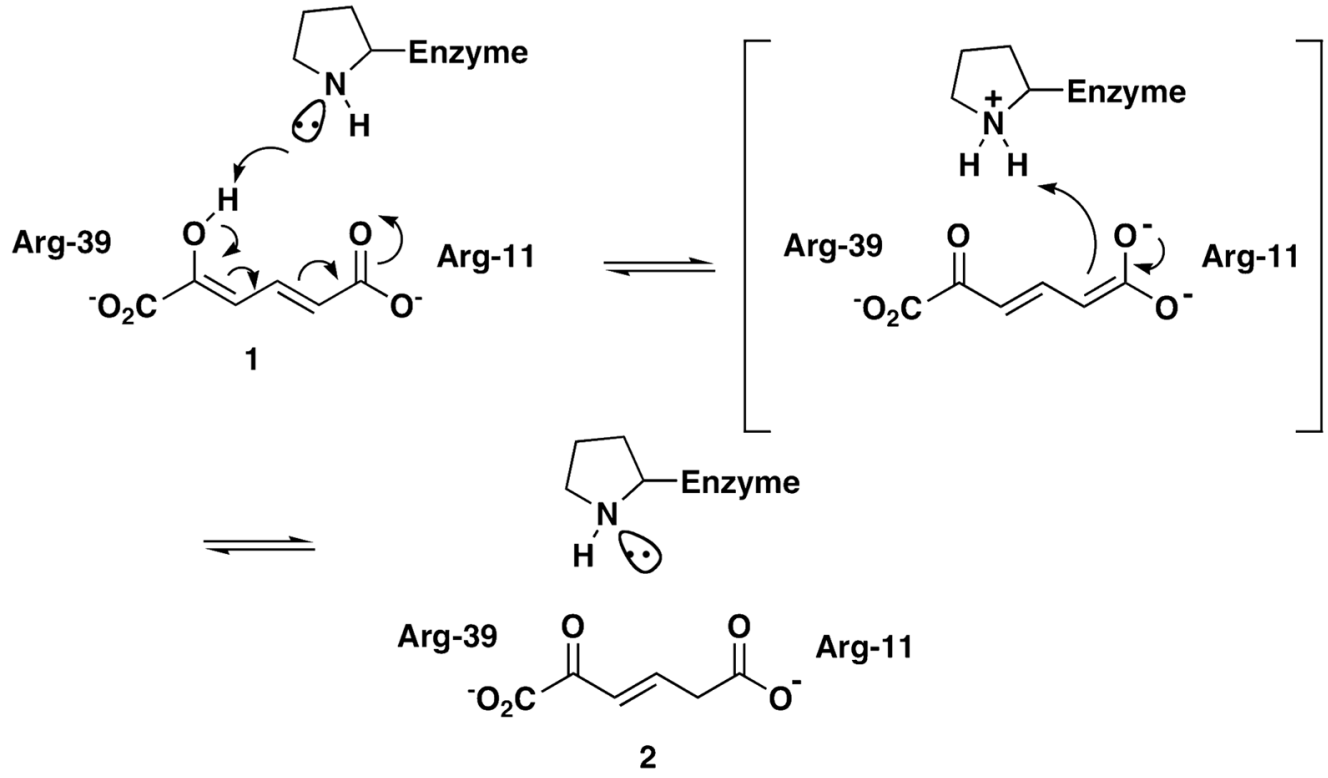

Scheme 3. 


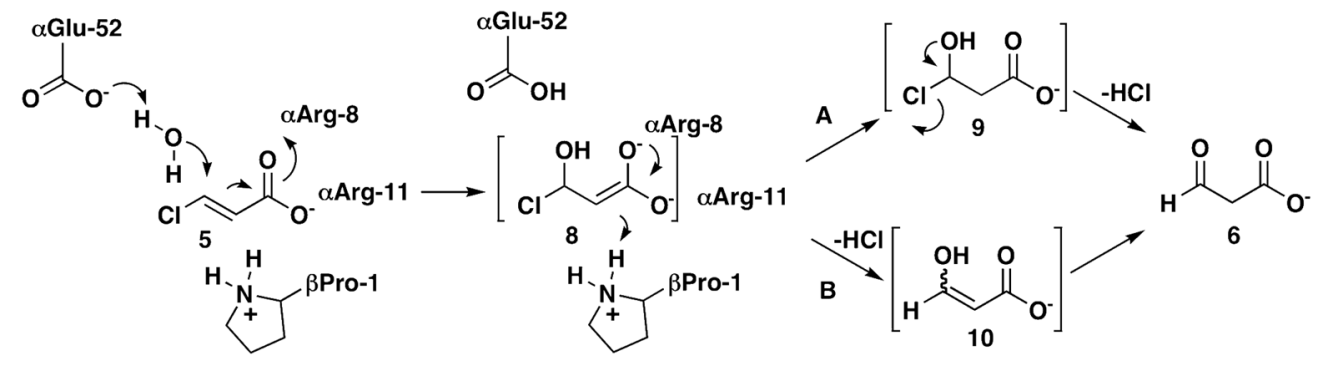

Scheme 4. 
<smiles>[O-]C([O-])=C[C+](Cl)CO</smiles>

$\mathrm{H}_{2} \mathrm{~N} \quad \mathrm{H}$ $+\because)-N-A r g-11$ or Arg-39

Scheme 5. 


\section{Table 1}

Data Collection and Refinement Statistics for hh4-OT.

\begin{tabular}{|c|c|}
\hline Data Collection & \\
\hline Space Group & $P 3_{1}$ \\
\hline \multicolumn{2}{|l|}{ Unit Cell Dimensions } \\
\hline a, b, c $(\AA)$ & $106.1,106.1,110.0$ \\
\hline$\alpha=\beta=\gamma($ degrees $)$ & $90,90,120$ \\
\hline Resolution ( & $91.85-2.41$ \\
\hline No. Reflections Observed & 297,700 \\
\hline No. Unique Reflections & 49,737 \\
\hline $\mathrm{R}_{\text {merge }}(\%)$ & $7.2(43.9)^{a}$ \\
\hline$I / \sigma(I)$ & $27.6(4.1)^{a}$ \\
\hline$\%$ Completeness & $98.6(88.9)^{a}$ \\
\hline \multicolumn{2}{|l|}{ Refinement } \\
\hline Resolution Range $(\AA)$ & $91.85-2.41$ \\
\hline No. Reflections in Working Set & 47,067 \\
\hline No. Reflections in Test Set & 2,670 \\
\hline $\mathrm{R}_{\text {work }}(\%)$ & 20.0 \\
\hline $\mathrm{R}_{\text {free }}(\%)$ & 25.0 \\
\hline Average B-factor $\left(\AA^{2}\right)$ & 32.1 \\
\hline Protein & 31.70 \\
\hline Ions & 59.60 \\
\hline Water & 32.80 \\
\hline \multicolumn{2}{|l|}{ RMS Deviation: } \\
\hline Bond length $(\AA)$ & 0.026 \\
\hline Bond angles (degrees) & 2.23 \\
\hline Protein/Water Atoms & $5447 / 249$ \\
\hline
\end{tabular}

${ }^{a}$ The last resolution shell is shown in parentheses. 
Table 2

Kinetic Parameters for 4-Oxalocrotonate Tautomerases using 2-Hydroxymuconate $(1)^{a}$.

\begin{tabular}{|c|c|c|c|}
\hline enzyme & $k_{\text {cat }}\left(\mathrm{s}^{-1}\right)$ & $K_{\mathrm{m}}(\mu \mathrm{M})$ & $k_{\mathrm{cat}} / K_{\mathrm{m}}\left(\mathrm{M}^{-1} \mathrm{~s}^{-1}\right)$ \\
\hline hh4-OT ${ }^{b}$ & $3000 \pm 100$ & $70 \pm 8$ & $4.3 \times 10^{7}$ \\
\hline$\alpha \mathrm{R} 12 \mathrm{~A}$ & $43 \pm 19$ & $1033 \pm 510$ & $4.2 \times 10^{4}$ \\
\hline$\alpha \mathrm{R} 40 \mathrm{~A}$ & $65 \pm 14$ & $345 \pm 100$ & $1.9 \times 10^{5}$ \\
\hline$\beta \mathrm{P} 1 \mathrm{~A}$ & $36 \pm 1$ & $17 \pm 2$ & $2.1 \times 10^{6}$ \\
\hline$\beta R 11 \mathrm{~A}$ & $3500 \pm 100$ & $69 \pm 7$ & $5.1 \times 10^{7}$ \\
\hline$\beta R 39 A$ & $733 \pm 67$ & $135 \pm 27$ & $5.4 \times 10^{6}$ \\
\hline 4-OT & $4000 \pm 182$ & $62 \pm 8$ & $6.5 \times 10^{7}$ \\
\hline
\end{tabular}

${ }^{a}$ The steady-state kinetic parameters were determined in $10 \mathrm{mM}$ potassium phosphate buffer $(\mathrm{pH} 7.3)$ at $24^{\circ} \mathrm{C}$.

${ }^{b}$ Errors are standard deviations. 
Table 3

Kinetic Parameters for 4-Oxalocrotonate Tautomerases using Phenylenolpyruvate (3) ${ }^{a}$.

\begin{tabular}{cccc}
\hline enzyme & $\boldsymbol{k}_{\text {cat }}\left(\mathbf{s}^{-\mathbf{1}}\right)$ & $\boldsymbol{K}_{\mathbf{m}}(\boldsymbol{\mu M})$ & $\boldsymbol{k}_{\text {cat }} / \boldsymbol{K}_{\mathbf{m}}\left(\mathbf{M}^{-\mathbf{1}} \mathbf{s}^{-\mathbf{1}}\right)$ \\
\hline hh4-OT $^{b}$ & $13 \pm 1$ & $121 \pm 20$ & $1.1 \times 10^{5}$ \\
$\alpha \mathrm{R} 12 \mathrm{~A}$ & $0.6 \pm 0.2$ & $143 \pm 80$ & $4.2 \times 10^{3}$ \\
$\alpha \mathrm{R} 40 \mathrm{~A}$ & $44 \pm 8$ & $152 \pm 40$ & $2.9 \times 10^{5}$ \\
$\beta$ P1A & $0.2 \pm 0.04$ & $63 \pm 22$ & $3.2 \times 10^{3}$ \\
$\beta R 11 \mathrm{~A}$ & $17 \pm 3$ & $198 \pm 49$ & $8.6 \times 10^{4}$ \\
$\beta$ R239A & $11 \pm 1$ & $159 \pm 24$ & $7.0 \times 10^{4}$ \\
4-OT & $73 \pm 6$ & $199 \pm 23$ & $3.7 \times 10^{5}$ \\
\hline
\end{tabular}

${ }^{a}$ The steady-state kinetic parameters were determined in $10 \mathrm{mM}$ potassium phosphate buffer $(\mathrm{pH} 7.3)$ at $24^{\circ} \mathrm{C}$.

${ }^{b}$ Errors are standard deviations. 